\title{
Crystallographic and shape orientations of magnetite micro-inclusions in plagioclase
}

\author{
Olga Ageeva ${ }^{1,2} \oplus \cdot$ Ge Bian $^{1} \cdot$ Gerlinde Habler $^{1} \cdot$ Alexey Pertsev $^{2} \cdot$ Rainer Abart $^{1}$
}

Received: 15 June 2020 / Accepted: 5 September 2020 / Published online: 23 September 2020

(c) The Author(s) 2020

\begin{abstract}
Plagioclase hosted, oriented magnetite micro-inclusions are a frequently observed phenomenon in magmatic and metamorphic rocks. Understanding the orientation relationships between these inclusions and the plagioclase host is highly relevant for interpreting paleomagnetic measurements. The systematics of the shape and crystallographic orientation relationships between needle- and lath-shaped magnetite micro-inclusions and their plagioclase host from oceanic gabbro were investigated using optical microscopy including universal stage measurements, scanning electron microscopy, and crystal orientation analysis by electron backscatter diffraction. The magnetite inclusions show preferred shape orientations following six welldefined directions and with specific crystallographic orientation relationships to the plagioclase host. These relationships are rationalized based on angular and dimensional similarities between the crystal structures of magnetite and plagioclase, which favor the parallel alignment of oxygen layers with similar lattice spacing in both phases. The parallel alignment of oxygen layers in plagioclase and magnetite can be traced back to the oriented nucleation of magnetite, which occurs by the accommodation of $\mathrm{FeO}_{6}$ octahedra in six-membered rings of $\mathrm{SiO}_{4}$ and $\mathrm{AlO}_{4}$ tetrahedra of the plagioclase structure. The orientation systematics of the magnetite micro-inclusions is related to four orientation variants for placing the $\mathrm{FeO}_{6}$ octahedra into the plagioclase structure.
\end{abstract}

Keywords Plagioclase $\cdot$ Magnetite inclusions - Shape orientation relationships $\cdot$ Crystallographic orientation relationships $\cdot$ Crystal structures $\cdot$ Oxygen layers

\section{Introduction}

Oriented micro-inclusions of $\mathrm{Fe}-\mathrm{Ti}$ oxide minerals such as magnetite, ulvospinel, hematite, and ilmenite hosted in rockforming silicate minerals are frequently observed in igneous and metamorphic rocks (Poldervaart and Gilkey 1954; Divljan 1960; Neumann and Christie 1962; Armbrustmacher and Banks 1974; Sobolev 1990; Usui et al. 2006; Wenk et al, 2011; Biedermann, et al. 2016; Ageeva et al. 2016, 2017).

Communicated by Othmar Müntener.

Olga Ageeva

olga.ageeva@univie.ac.at

1 Department of Lithospheric Research, University of Vienna, Althanstrasse 14, 1090 Wien, Austria

2 Institute of Geology of Ore Deposits, Petrography, Mineralogy, and Geochemistry, Russian Academy of Sciences (IGEM RAS), Staromonetnyi 35, Moscow 119017, Russia
The Fe-Ti oxide micro-inclusions most likely precipitate within the silicate minerals that originally crystallized with high Fe and Ti contents from evolved melt (Natland et al. 1991) and became supersaturated with respect to $\mathrm{Fe}-\mathrm{Ti}$ oxide minerals during cooling (Okamura et al. 1976) and/ or under changing oxygen fugacity (Doukhan et al. 1990; Ashworth and Chambers 2000). Alternatively, igneous rocks may get metasomatized by interaction with evolved Fe- and Ti-rich melts or fluids during the late magmatic stages, which induces precipitation of $\mathrm{Fe}-\mathrm{Ti}$ oxide micro-inclusions in the pre-existing silicate minerals (Trindade et al. 1999, 2001; Diot et al. 2003; Bolle et al. 2003; Malpas and Robinson 1997; Grimes et al. 2008; Hekinian 2014).

Among the Fe-Ti oxide minerals, magnetite is of particular interest in the context of paleomagnetism. Magnetite is ferrimagnetic with a Curie temperature of $580{ }^{\circ} \mathrm{C}$, and it is the main carrier of the natural remanent magnetization of rocks (Dunlop and Ozdemir 1997, 2007; Tauxe 2010). In this context, the temperature at which the oriented magnetite inclusions formed is of crucial importance. Considering the 
magnetocrystalline anisotropy of magnetite, also the shape and crystallographic orientation relationships between the magnetite micro-inclusions and the plagioclase host are of interest.

In clinopyroxene, magnetite inclusions primarily occur as elongated plates lying parallel to the (010) plane of the clinopyroxene and show two well-defined elongation directions (Bown and Gay 1959; Okamura et al. 1976; Harlow and Klimentidis 1980; Fleet et al. 1980; Woensdregt et al. 1983; Doukhan et al. 1990; Renne et al. 2002; Feinberg et al. 2004; Hwang et al. 2010), which ensure perfectly coherent magnetite-clinopyroxene interfaces according to the optimum phase boundary model of Bollmann (1970). A geo-thermometer reflecting the temperature of magnetite precipitation was calibrated based on the notion that, due to the difference in thermal expansivity between magnetite and clinopyroxene, the angle between the two elongation directions is temperature dependent (Fleet et al. 1980; Doukhan et al. 1990; Feinberg et al. 2004).

When present as $\mu \mathrm{m}$ - and sub- $\mu \mathrm{m}$-sized crystals, magnetites behave as single-domain or pseudo single-domain grains, where a primary remanent magnetization is very difficult to change (Dunlop and Ozdemir 1997, 2007; Tauxe 2010). The presence of abundant needle- or lath-shaped magnetite micro-inclusions in plagioclase and pyroxene of anorthosites and gabbros leads to the particularly stable natural remanent magnetization of these rocks (Evans et al. 1968; Sobolev and Faynberg 1990; Renne et al. 2002; Gee and Meurer 2002; Feinberg et al 2005, 2006a; Tarduno et al. 2006; Ebert et al. 2010; Muxworthy and Evans 2013; Usui et al. 2015; Calvín et al. 2017). In the context of paleomagnetic measurements, understanding the crystallographic and shape orientation relationships between oriented magnetite micro-inclusions and the respective host crystal is important, because in an imposed magnetic field, it is considerably more difficult to saturate the magnetization of a magnetite along the "magnetically hard axes" $<100>$ than along the magnetically "easy axes" $<111>$ (Dunlop and Ozdemir 1997). Given that the magnetite micro-inclusions show distinct orientations in the plagioclase and pyroxene host crystals, the inherent magnetocrystalline anisotropy of magnetite may lead to anisotropic susceptibility of the entire inclusion-host assemblage and thus put a bias on the preservation of an externally imposed magnetic field. This phenomenon is of particular relevance, if single crystal paleomagnetic measurements are made (Cottrell and Tarduno 1999; Tarduno et al. 2006).

In this communication, we address oriented magnetite micro-inclusions in plagioclase from oceanic gabbros. Needleshaped magnetite micro-inclusions lying in the (112), (150), and (150) planes of plagioclase were first described for aventurine feldspar by Andersen (1915). Later, Sobolev (1990) discerned five types of orientation of needle-shaped magnetite micro-inclusions and systematized their shape orientation relationships. The study of Sobolev (1990) is based on optical microscopy and gives only limited information on the underlying crystallographic orientation relationships. Wenk et al. (2011) used crystal orientation analysis by electron backscatter diffraction (EBSD) and Laue diffraction to determine the crystallographic orientation relationships between needle- and lath-shaped magnetite micro-inclusions and their plagioclase host. These latter authors focused on needle-shaped magnetite inclusions with their elongation direction parallel to the [001] direction of the plagioclase host and suggested a model relating this orientation to the presence of abundant magnetite nucleation sites along channels in the plagioclase structure running parallel to pl[001]. In our study, we combine crystal orientation analysis by EBSD, optical microscopy including U-stage measurements, and scanning electron microscopy (SEM) to complement the observations made by Sobolev (1990) and Wenk et al. (2011). We combine information on the shape and crystallographic orientation relationships of all the orientation types reported by Sobolev (1990) and Wenk et al. (2011) and put these observations into a common framework that is based on the underlying crystallographic relationships.

\section{Sampling and methods}

\section{Sampling}

The plagioclases investigated in this study are from oceanic gabbros that were dredged at the Mid Atlantic Ridge between $10^{\circ} \mathrm{N}$ and $14^{\circ} \mathrm{N}$ during the 2005-2009 cruises of the R.V. Professor Logachev (Beltenev et al. 2007,2009; Cipriani et al. 2009; Pertsev et al. 2012). The gabbro samples L2612-41 and L2612-47 were collected from classical oceanic crust of the Vema lithospheric section (Bonatti et al. 2005). Other samples are from gabbro-peridotite Oceanic Core Complexes (OCCs) exhumed in footwalls of largeoffset extensional faults (" $13^{\circ} \mathrm{N}$ OCC" and " $13^{\circ} 30^{\prime} \mathrm{N}$ OCC", Smith et al. 2008). Two groups of gabbros were sampled. One group is represented by rocks with simple geological history including the non-altered sample L30-277-10 and the hydrothermally altered sample L30-277-7. The other group is represented by rocks with more complex petrogenetic history including gabbros intruded by plagiogranite veinlets (Sample L32-101-1) and gabbros with multi-stage late-magmatic and high-temperature hydrothermal alteration (Samples L2612-41 and L2612-47).

\section{Optical microscopy and universal stage measurements}

Polished thin sections with chemo-mechanical finish were prepared from all samples and investigated by polarization microscopy using both transmitted and reflected light. A 
4-axis universal stage was used for determining the shape orientation of the needle- or lath-shaped magnetite microinclusions. In a first step, the microscope table was rotated to put a magnetite needle into the $\mathrm{N}-\mathrm{S}$ orientation in the microscope image. In a second step, the thin section was tilted around two mutually perpendicular axes of the U-stage to bring the elongation direction of the inclusion into parallel alignment with the microscope axis or into horizontal position, depending on the inclination of the elongation direction with respect to the sample surface. In replicate measurements, the orientation of the elongation directions of individual inclusions could be reproduced within $2^{\circ}-7^{\circ}$.

\section{Electron backscatter diffraction (EBSD)}

The crystallographic orientations of plagioclase and magnetite crystals with respect to the sample reference system were determined using EBSD. The EBSD analyses were performed on an FEI Quanta 3D FEG-SEM at the laboratory for scanning electron microscopy and focused ion beam (FIB) applications of the Faculty of Geosciences, Geography and Astronomy at the University of Vienna (Austria). The SEM has a Schottky-type field emission electron source and is equipped with an EDAX Digiview 5 EBSD camera mounted at an elevation angle of $5^{\circ}$. The thin section samples were carbon coated and were at $70^{\circ}$ stage tilt and 14-14.5 mm working distance. The EBSD analyses were performed in high vacuum mode. The electron beam was operated at $15 \mathrm{kV}$ accelerating voltage and c. $4 \mathrm{nA}$ probe current in the analytical beam mode. The EBSD camera resolution was set to $4 \times 4$ binning, yielding a Kikuchi pattern resolution of $215 \times 215$ pixels. Different camera gain settings were applied for analyzing plagioclase and magnetite to account for the strongly differing signal intensities of the two phases. Static and dynamic background filters were applied along with a grayscale normalization filter to optimize image contrast of the Kikuchi patterns. All crystal orientation data were collected as single points using the software EDAX OIM DC 7.3.1., where the Hough transform settings (binned pattern size, Rho-fraction, minimum peak distance and the maximum number of reflectors used) were adjusted for each analysis point. A minimum number of 3 reflectors were used for indexing, whereas the maximum number of reflectors varied between 13 and 18. Only the band center position was considered for indexing, and the interplanar angle tolerance was set to $2^{\circ}$. Measured band triplets were indexed by automatized comparison with the references structures of plagioclase as triclinic [P-1]; $a=8.152 \AA, b=12.834 \AA$, $\mathrm{c}=7.079 \AA ; \alpha=93.49^{\circ}, \beta=116.13 \AA, \gamma=90.4 \AA$ (AMCS database 762 , Wenk et al. 1980), and magnetite as cubic [Fd-3 m]; a $=8.396 \AA$, $\alpha=90^{\circ}$ (TSL Materials Database). The statistics of each orientation solution (confidence index, Fit value and the total number of band triplets) were individually checked, and only those data that yielded an unambiguous orientation solution were stored. The crystal orientation data were processed using the software EDAX OIM Analysis 7.3.1 and the MatLab MTEX toolbox (Krakow et al. 2017). The AutoCAD software was used for 3D visualizations.

\section{Results}

\section{Sample petrography}

The mineral content of the gabbros is dominated by primary magmatic coarse-grained $(1-15 \mathrm{~mm})$ tabular plagioclase and prismatic and xenomorphic pyroxene, where most pyroxenes are clinopyroxene, and orthopyroxene is rare. In the altered gabbros, the initial grain shape is rarely preserved due to recrystallization and partial replacement by secondary minerals such as amphiboles and fine-grained polyphase mineral aggregates. The $\mathrm{Fe}-\mathrm{Ti}$ oxides are present as large interstitial grains of magnetite and as micron- and sub-micron-sized inclusions in plagioclase and pyroxene. Detailed descriptions of the mineralogy and petrography of the gabbros with complex petrogenetic history (Samples L32-101-1, L2612-41, L2612-47) can be found in Pertsev et al. (2015), Aranovich et al. (2015) and Ageeva et al. (2017).

The plagioclases from the studied gabbros contain abundant micrometer and sub-micrometer-sized needle- or lathshaped magnetite micro-inclusions (Fig. 1) with preferred shape orientations following distinct directions within the plagioclase host (Fig. 1a, b). The needles are present primarily in the internal portions of the plagioclase grains and are less common or missing in the rim regions and in the vicinity to contacts with plagiogranite veinlets or hydrothermal veins. Within a single inclusion, the magnetite usually has constant crystallographic orientation. It was shown by Ageeva et al. (2016) that in the course of hydrothermal overprint, the magnetite micro-inclusions may recrystallize, coarsen and assume more tabular shape. In addition, oriented sub-micrometer-sized lamellae of ilmenite and/or ulvospinel may be present within individual magnetite inclusion (Fig. 1c, d). The genesis of the ilmenite and ulvospinel lamellae has been discussed by Wenk et al. (2011), Tan et al. (2016), and Ageeva et al. (2016, 2017) and is not further addressed in this communication.

In this study, we focus on the most pristine sample (Sample L30-277-10), where the gabbro is devoid of any indications of hydrothermal alteration. In this sample, the microinclusions have pronounced needle shape with diameters of several $100 \mathrm{~nm}$, to about $1 \mu \mathrm{m}$ and a length of up to several $100 \mu \mathrm{m}$ (Fig. 1). The inclusions generally have aspect ratios of $>100$ and show strong shape preferred orientation with respect to the plagioclase host. The magnetite needles are 


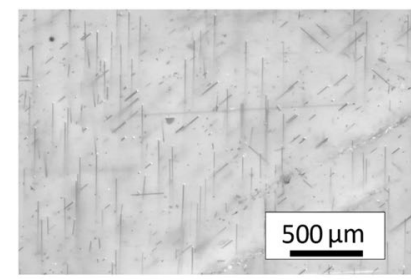

a

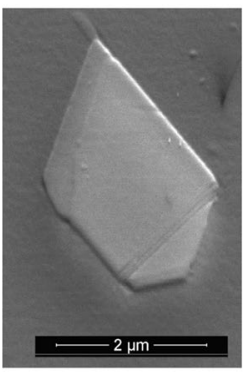

C

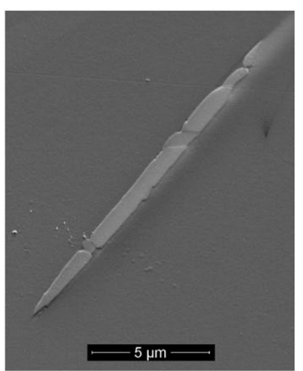

d

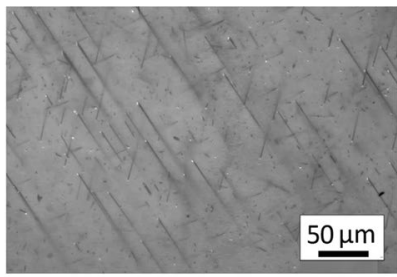

b

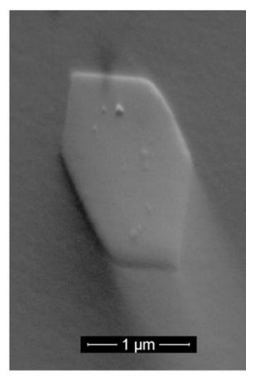

e
Fig. 1 a, b Photomicrographs of transmitted light overlain with a reflected light optical image showing plagioclase with needle-shaped magnetite micro-inclusions with shape-preferred orientations following several distinct directions in the plagioclase host. Sample L32277-10. c-e Secondary electron images of the micro-inclusions: ilmenite lamellas (gray) are enclosed in magnetite inclusions (light gray) in plagioclase (dark gray)

interpreted as being precipitates exsolved from an Fe-bearing plagioclase during cooling after magmatic crystallization (Wenk et al. 2011). The observed orientation relationships between the inclusions and the plagioclase host are considered as primary.

\section{Shape orientation relationships between the magnetite micro-inclusions and the plagioclase host}

About $90 \%$ of the magnetite micro-inclusions show shapepreferred orientations with their elongation directions following several well-defined directions in the plagioclase host (Fig. 2). U-stage measurements confirm the shape orientation relationships (SORs) that were previously identified by Sobolev (1990). The shape orientations of the magnetite needles correlate neither with typical growth facets of plagioclase nor with cleavage- or twinning planes. Five of the inclusion elongation directions are identified as being perpendicular to the $\mathrm{pl}(112), \operatorname{pl}(\overline{3} 12), \operatorname{pl}(1 \overline{5} 0), \operatorname{pl}(150)$ and $\mathrm{pl}(100)$ planes, and one coincides with the $\mathrm{pl}[001]$ direction (Fig. 2c). We refer to the different groups of orientations as orientation classes and use the notation "pl(112)n-mt",

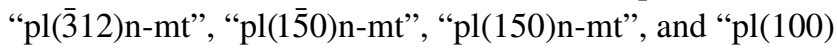
$\mathrm{n}$-mt" for the inclusions with their elongation directions normal to the respective plagioclase planes. These inclusions are categorized as the "plane-normal type". Furthermore, we denote the inclusions with their elongation directions parallel to the pl[001] direction as "pl[001]-mt" (Fig. 2c).

It is seen in the stereographic projection of Fig. $3 a$ that the $\mathrm{pl}[001]-\mathrm{mt}$ (labeled "F") and the pl(112)n-mt ("B") needles lie in the $\mathrm{pl}(1 \overline{5} 0)$ plane, the $\mathrm{pl}[001]-\mathrm{mt}$ ("F") and the $\mathrm{pl}(\overline{3} 12)$ n-mt ("C") needles lie in the $\mathrm{pl}(150)$ plane, the $\mathrm{pl}(112) \mathrm{n}-\mathrm{mt}$ ("B") and the pl(150)n-mt ("E") needles are closely parallel to the $\mathrm{pl}(\overline{3} 12)$ plane, and the $\mathrm{pl}(1 \overline{5} 0) \mathrm{n}-\mathrm{mt}$ ("D") and the $\mathrm{pl}(\overline{3} 12) n-m t$ ("C $C$ ") needles are closely parallel to the $\mathrm{pl}(112)$ plane. Finally, the pl(150)n-mt ("D") and $\mathrm{pl}(150) n-m t$ ("E") needles are parallel to the plane that is perpendicular to the $\mathrm{pl}[001]$ direction, which is close to the $\mathrm{pl}(\overline{4} \overline{1} 8)$ plane, and the less abundant pl(100)n-mt ("A") needles lie close to the $\mathrm{pl}(010)$ and the $\mathrm{pl}(\overline{4} \overline{1} 8)$ planes.

It is important to note that magnetite needles pertaining to all six shape orientation classes are present in the samples of the oceanic gabbros under study. Among the six orientation classes, the $\mathrm{pl}(112) \mathrm{n}-\mathrm{mt}$ and the $\mathrm{pl}(\overline{3} 12) \mathrm{n}-\mathrm{mt}$ needles are the most abundant. The plagioclase from the oceanic gabbro has compositions of labradorite to bytownite with anorthite contents of 60 to $70 \mathrm{~mol} \%$. For samples containing plagioclase with andesine composition (Samples L2612-41 and L2612-47), where the anorthite content is comparatively low (42-45 mol \%), the pl[001]-mt micro-inclusions are the dominating class representing more than $95 \%$ of the observed cases. Albite and oligoclase do not contain any magnetite micro-inclusions.

\section{Crystallographic orientation relationships between the magnetite micro-inclusions and the plagioclase host}

It has been shown by Ageeva et al. (2016) and is confirmed by our new measurements that the SORs between the magnetite needles and the plagioclase host are accompanied by systematic crystallographic orientation relationships (CORs). For example, for the pl[001]-mt inclusions, one of the $\mathrm{mt}<011>$ directions is parallel to the $\mathrm{pl}[001]$ direction and, at the same time, one of the $\mathrm{mt}<111>$ directions is parallel to $\mathrm{pl}(1 \overline{5} 0) \mathrm{n}$, and another one of the $\mathrm{mt}<011>$ directions is sub-parallel to $\mathrm{pl}(150) \mathrm{n}$. Thus, the orientation relationships are fixed, and this COR may be referred to as a specific COR (Griffiths et al. 2016; Habler and Griffiths 2017). In some cases, one of the $\mathrm{mt}<111>$ directions is parallel to $\mathrm{pl}(150) \mathrm{n}$ or $\mathrm{pl}(120) \mathrm{n}$. The latter one corresponds to the COR described by Wenk et al. (2011).

For all shape orientation classes of the plane-normal inclusions one of the $\mathrm{mt}<111>$ directions is parallel to the elongation direction of the inclusion (Fig. 4) and thus to the plane normal of either the $\mathrm{pl}(112), \operatorname{pl}(\overline{3} 12), \operatorname{pl}(1 \overline{5} 0), \operatorname{pl}(150)$, or the $\mathrm{pl}(100)$ plane, depending on shape orientation class. The orientations of the $\mathrm{pl}(112) \mathrm{n}-\mathrm{mt}, \mathrm{pl}(\overline{3} 12) \mathrm{n}-\mathrm{mt}, \mathrm{pl}(1 \overline{5} 0)$ $\mathrm{n}-\mathrm{mt}$, and the $\mathrm{pl}(150) \mathrm{n}-\mathrm{mt}$ inclusions show rotation around 
Fig. 2 a, b Part of plagioclase grain (optical image, transmitted light) with color-coded inclusion elongation directions (a) and without color coding (b); the color coding in figure (a) corresponds to the color coding in figure (c). c Elongation directions plotted in stereographic projection (upper hemisphere): all color coded inclusions pertain to one of the six identified orientation classes representing about $90 \%$ of the needle-shaped micro-inclusions; the remaining inclusions are shown in white and are elongated closely parallel to the directions [ $[\overline{5} \overline{1} 3]$ or $[\overline{5} 1 \overline{8}]$ of the plagioclase host. d, $\mathbf{e}$ Stereographic projections of the orientation distribution function (ODF, halfwidth: 3 degrees) of the $\{111\}$ and $\{011\}$ planes of magnetite micro-inclusions, represented in figures $(\mathbf{a}-\mathbf{c})$; the data set comprises EBSD measurements of 92 magnetite grains. The EBSD data cannot be regarded as statistically representative, because a bias is implied by the orientation of the cut, and several cuts with different orientations would be needed to obtain statistically valid data on the relative abundances of inclusions of the different orientation classes

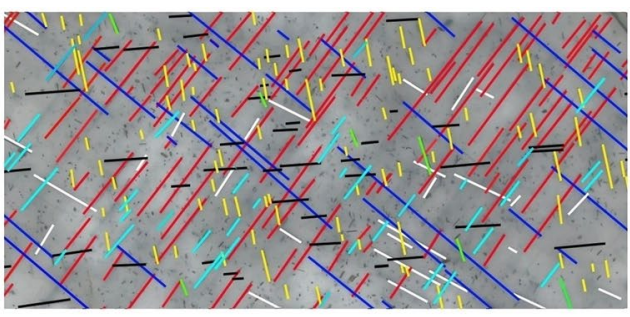

a

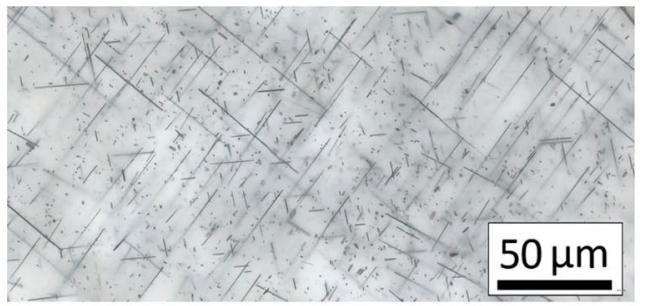

b

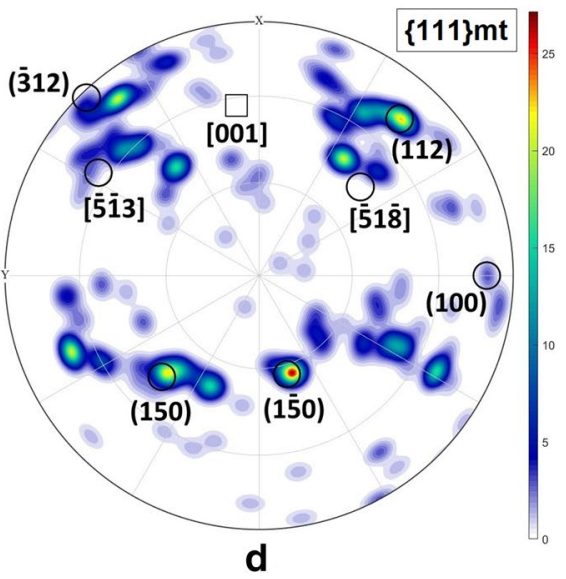

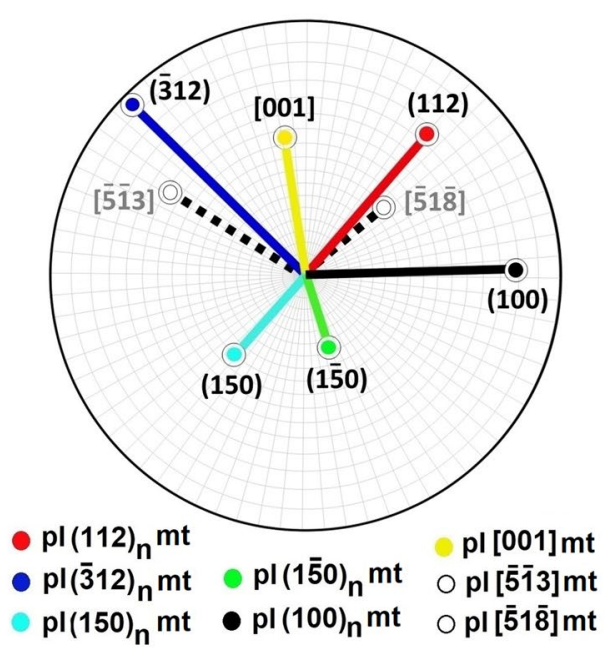

C

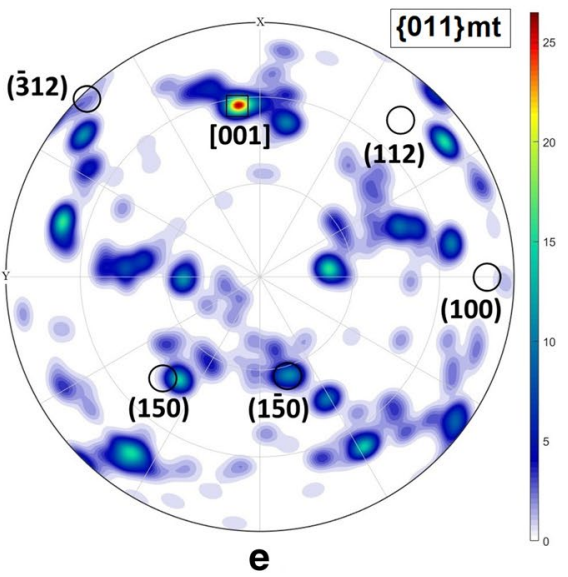

their elongation direction, which corresponds to one of the $\mathrm{mt}<111>$ directions. We refer to those inclusions of the plane-normal type that only have one orientation match with the plagioclase host as being in "general orientation".

For each shape orientation class of the plane-normal inclusions, a subset of inclusions has additional orientation matches with the plagioclase host, so that a specific COR between the magnetite and the plagioclase host results. For example, a subset of the pl(112)n-mt inclusions show a specific COR with one of the $\mathrm{mt}\{011\}$ planes parallel to the $\mathrm{pl}(1 \overline{5} 0)$ plane and another one sub-parallel to the $\mathrm{pl}(\overline{3} 12)$ plane, in addition to the alignment of one of the $\operatorname{mt}\{111\}$ planes with the pl(112) planes. Similarly, a subset of the $\mathrm{pl}(\overline{3} 12) n-m t$ inclusions have one of the $\mathrm{mt}\{011\}$ planes parallel to the $\mathrm{pl}(112)$ plane and another one of the $\operatorname{mt}\{011\}$ planes parallel to the $\mathrm{pl}(150)$ plane, in addition to the alignment of one of the $\mathrm{mt}\{111\}$ planes with the $\mathrm{pl}(\overline{3} 12)$ plane (Fig. 4b). We refer to those inclusions that have such specific COR with the plagioclase host as being in "main orientation". Furthermore, for the pl(112)n-mt and the pl(150)n-mt inclusions, an additional specific COR exists, where one of the $\mathrm{mt}<001>$ directions is parallel to pl[14 10 7] and for the $\mathrm{pl}(\overline{3} 12) \mathrm{n}-\mathrm{mt}$ and for the $\mathrm{pl}(150) \mathrm{n}-\mathrm{mt}$ inclusions one of the $\mathrm{mt}<001>$ directions is parallel to pl[1/4 10 $\overline{7}]$. These CORs are linked to specific orientation variants for placing structural elements of the crystal structure of magnetite into the plagioclase structure and are referred to as the "nucleation orientation", which is also a specific COR (see further down). Finally, the pl(100)n-mt needles have strong orientation relationships with one of the $\mathrm{mt}<111>$ directions parallel to the $\mathrm{pl}(100) \mathrm{n}$ and another one of the $\mathrm{mt}<111>$ directions parallel to the $\mathrm{pl}(1 \overline{5} 0) \mathrm{n}$ and one of the $\mathrm{mt}<011>$ directions parallel to $\mathrm{pl}[001]$. In addition, for the $\mathrm{pl}(100) \mathrm{n}-\mathrm{mt}$ needles, one of the $\mathrm{mt}<001>$ directions is parallel to $\mathrm{pl}\left[\begin{array}{l}14 \\ 10\end{array}\right.$ 7], which corresponds to a nucleation orientation (Fig. 4a). Note for a particular shape orientation class any general crystallographic orientation is related to the main orientation and to the nucleation orientation by rotations around their elongation direction, which coincides with one of the $\mathrm{mt}<111>$ directions. The CORs of the most abundant shape orientation classes in general-, main-, and nucleation orientation are listed in Table 1. The shape and 


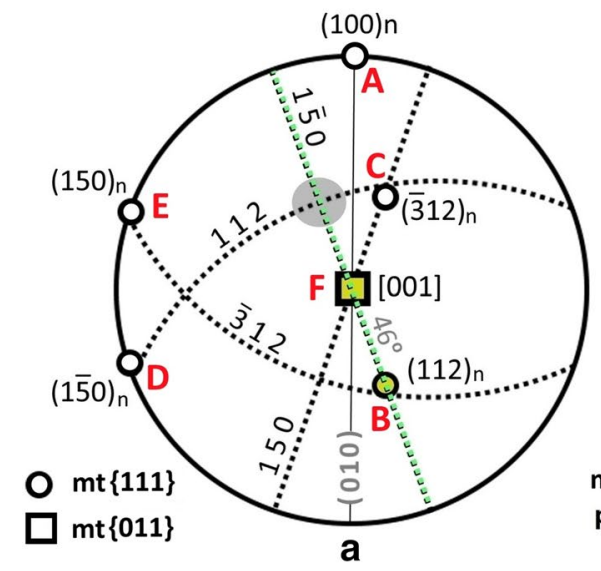

Fig. 3 a Stereographic projection (upper hemisphere) showing the crystallographic orientation relationships between plagioclase and the six most abundant orientation classes of magnetite micro-inclusions. Five shape orientation classes are characterized by having their elongation directions normal to the plagioclase (112), (150), (150), $(\overline{3} 12)$ and (100) lattice planes. The poles of these planes are indicated by the Miller indices with subscript " $n$ ", and the corresponding great circles are shown as dashed lines. For the magnetite needles pertaining to these orientation classes, one of the magnetite $<111>$ directions (open circles) is parallel to the needle elongation direction. The sixth orientation class has its elongation direction parallel to the pla-

crystallographic orientation relationships for some of these shape orientation classes are illustrated in Fig. 4.

In rare cases, one of the $\mathrm{mt}<001>$ directions is parallel to the $\mathrm{pl}\left[\begin{array}{ll}0 & 2\end{array}\right]$, the $\mathrm{pl}[0 \overline{2} 3]$, the $\mathrm{pl}[4 \overline{6} 9]$, or the $\mathrm{pl}[9 \overline{2} 0]$ direction. These arrangements also correspond to possible nucleation positions (see further down).

\section{Orientations of the magnetite-plagioclase interfaces}

In cross sections of magnetite needles appearing on the polished sample surface, the magnetites are bound by straight interfaces, indicating that the magnetite-plagioclase interfaces are faceted. The orientations of the planar interface segments were determined by combining the orientations of their traces on the polished sample surface as seen on SE images, crystal orientation information as obtained from EBSD, and elongation directions as obtained from U-stage measurements. The rationale underlying the construction is that the needles, which typically have aspect ratios $>100$, are bound by prismatic planes containing the elongation direction. Given the high aspect ratios of the needles, the likelihood for the perimeter of a needle cross section appearing on the polished sample surface to be comprised of the traces of these prismatic planes is very high. Assuming that the straight segments of the magnetite-plagioclase interfaces in cross section are contained in prismatic planes, which also contain the elongation direction, the interface plane can be constructed from the direction of the

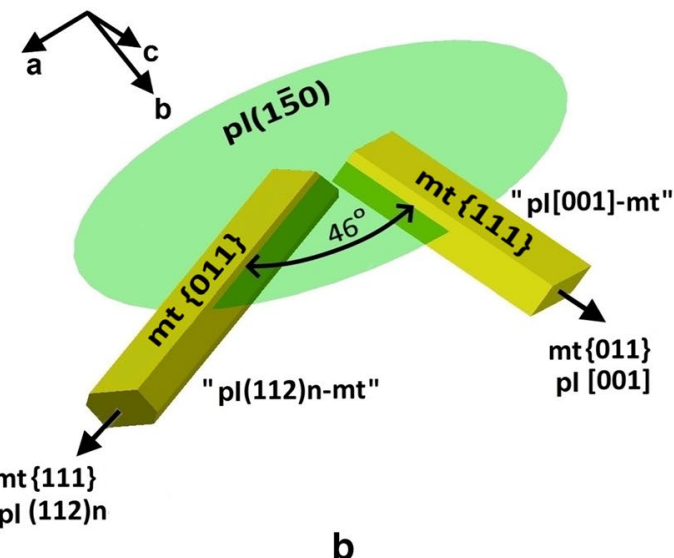

gioclase [001] direction, and one of the magnetite $<011>$ directions (open square) is parallel to the needle elongation direction and thus to plagioclase [001]. The gray circle indicates the viewing direction used in Fig. 6. b Perspective view of a pl(112)n-mt and a pl[001]-mt inclusion, which lie in the $\mathrm{pl}(1 \overline{5} 0)$ plane (green disc); the corresponding large circle is shown as the green dashed line in $\mathbf{a}$; one of the $\operatorname{mt}\{011\}$ facets of the $\mathrm{pl}(112) \mathrm{n}-\mathrm{mt}$ inclusion and one of the $\operatorname{mt}\{111\}$ facets of the $\mathrm{pl}[001]$-mt inclusion are parallel to the plagioclase $(150)$ plane. The elongation directions of the two needle types enclose an angle of $46^{\circ}$

linear segment of the trace of the magnetite-plagioclase interface on the sample surface and the elongation direction. Both these directions can be tied to the crystallographic orientations of the magnetite and plagioclase crystals based on the crystal orientation information from EBSD.

In Fig. 5, the results of this construction are shown for a pl(112)n-mt inclusion and for a pl[001]-mt inclusion (see also Fig. 3b), both in main orientation. The pl(112)n-mt inclusion is bound by $\mathrm{mt}\{111\}$ facets, which are aligned parallel to the $\mathrm{pl}(1 \overline{5} 0)$ plane, and by $\mathrm{mt}\{011\}$ facets, which are sub-parallel to the $\mathrm{pl}(\overline{3} 12)$ plane. The $\mathrm{pl}[001]-\mathrm{mt}$ inclusion is bound by $\mathrm{mt}\{111\}$ facets which are parallel to $\mathrm{pl}(1 \overline{5} 0)$, and by $\mathrm{mt}\{011\}$ facets, which are parallel to $\mathrm{pl}(150)$. Furthermore, the $\mathrm{pl}(\overline{3} 12) \mathrm{n}-\mathrm{mt}$ inclusions in main orientation were found to be bound by the $\mathrm{pl}(150)$ and $\mathrm{pl}(112)$ planes, each of which coincides with one of the $\mathrm{mt}\{011\}$ planes. The $\mathrm{pl}(1 \overline{5} 0) \mathrm{n}-\mathrm{mt}$ inclusions in main orientation were found to be bound by the $\mathrm{pl}(112)$ plane, which coincides with one of the $\mathrm{mt}\{011\}$ planes, and the $\mathrm{pl}(150) \mathrm{n}-\mathrm{mt}$ inclusions in main orientation were found to be bound by the $\mathrm{pl}(\overline{3} 12)$ plane, which coincides with one of the $\mathrm{mt}\{011\}$ planes.

\section{Discussion}

The salient features of the plagioclase-hosted magnetite micro-inclusions may be summarized as: (i) the elongation directions of the micro-inclusions correspond to specific 
Fig. 4 Shape and crystallographic orientation relationships between magnetite microinclusions and plagioclase host. Secondary electron image (SE) and optical microscope image $(\mathrm{OM})$ of the corresponding micro-inclusions are shown for reference. Solid lines indicate the elongation directions of the magnetite needles. a pl(100) n-mt (marked "A", plot on the left), pl(112)n-mt (marked "B") and $\mathrm{pl}(\overline{3} 12)$ n-mt (marked "C") (plot on the right) inclusions. b $\mathrm{pl}(\overline{3} 12) \mathrm{n}-\mathrm{mt}$ inclusions in main (light blue symbols, marked " $\mathrm{C}_{\mathrm{M}}$ ") and in nucleation (blue symbols, marked " $\mathrm{C}_{\mathrm{N}}$ ") orientation; the dashed large circle corresponds to the traces of poles undergoing the rotation around $\mathrm{mt}\langle 111\rangle$, the black arrows indicate the rotation relating the main and the nucleation orientation. $\mathbf{c}$ pl $(1 \overline{5} 0)$ n-mt (marked "D") and pl(112) $n$-mt (marked "B") inclusions in the same plagioclase host, both are in "nucleation orientation". Note also the alignment of the $\mathrm{mt}[001]$ and $\mathrm{pl}\left[\begin{array}{ll}14 & 107]\end{array}\right.$ for the needle "A" in $\mathbf{a}$
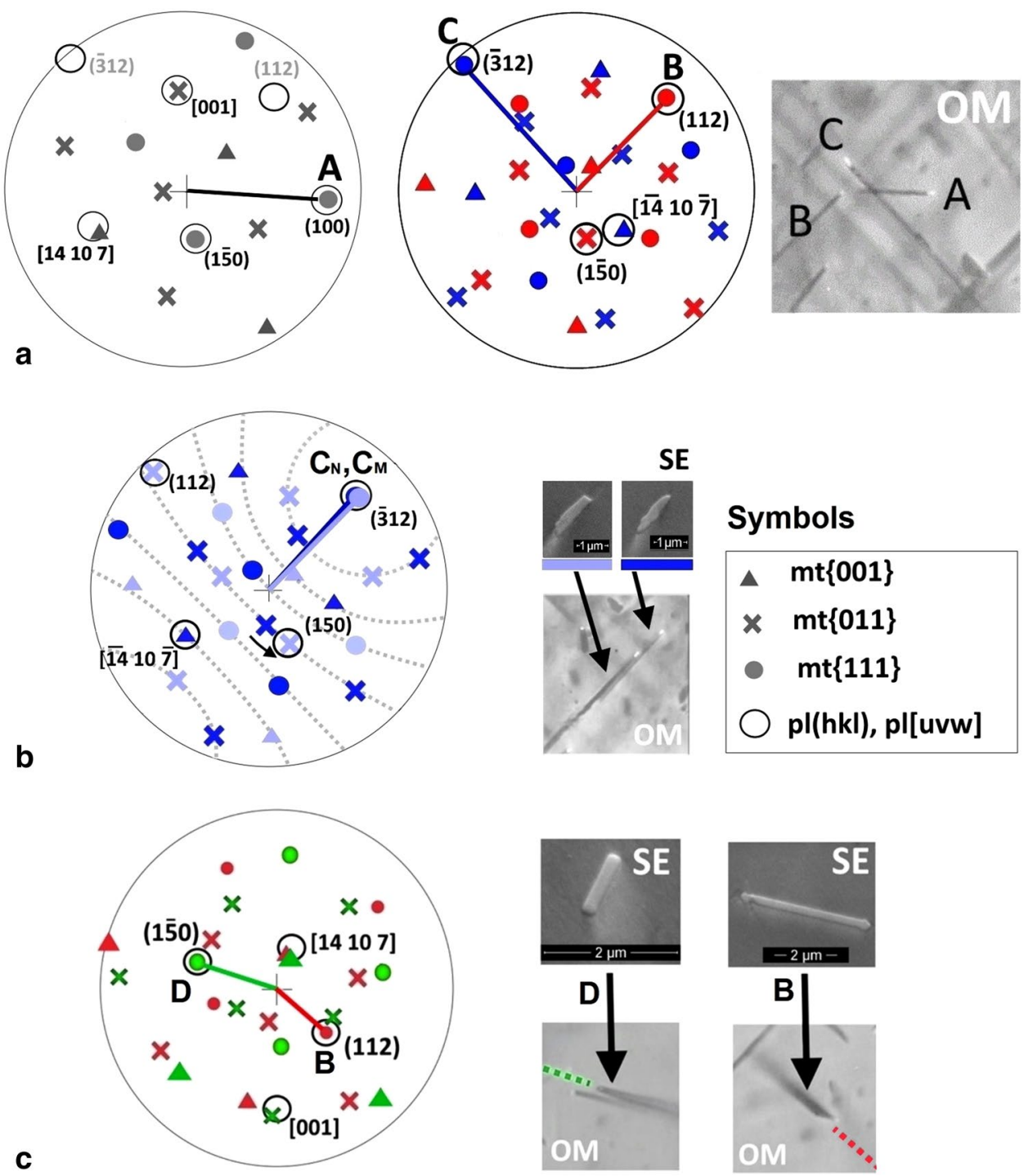

directions in the plagioclase host. In the samples under study, about $90 \%$ of the micro-inclusions show this directional coincidence. Based on their orientation relationships with the plagioclase host, they are grouped into six shape orientation classes, five orientation classes are of the plane-normal type with their elongation directions perpendicular to the $\mathrm{pl}(112), \operatorname{pl}(\overline{3} 12), \operatorname{pl}(1 \overline{5} 0), \operatorname{pl}(150)$ or the $\mathrm{pl}(100)$ planes, respectively, and one orientation class is represented by needles with their elongation direction parallel to the $\mathrm{pl}[001]$ direction. (ii) The elongation direction of the magnetite needles coincides with either one of the $\mathrm{mt}<111>$ or one of the $\mathrm{mt}<011>$ directions, depending on the shape orientation class. (iii) The micro-inclusions have quite stable crystallographic orientation parallel to the needle elongation direction, the needles with elongation direction perpendicular to the $\operatorname{pl}(112), \operatorname{pl}(\overline{3} 12)$, $\mathrm{pl}(1 \overline{50})$, and $\mathrm{pl}(150)$ planes show rotation around the elongation direction. (iv) A subset of the micro-inclusions of each shape orientation class has specific orientation relationships with the plagioclase host. (v) The micro-inclusions of one orientation class that have specific CORs to the plagioclase host are often bound by plagioclase planes, the normal directions of which are parallel to the elongation directions of magnetite micro-inclusions pertaining to the other orientation classes.

According to the theory of interfaces in crystalline materials (Bollmann 1970; Sutton and Balluffi 1995), the shape and the shape orientation of a solid phase precipitate forming in a host crystal are controlled by the similarity between the crystal structures of the precipitate and the host phase. The orientations of the phase boundaries essentially depend on the dimensional fit of the space lattices of the two phases. In the following, we discuss simple geometrical concepts that help to rationalize the systematic SORs and CORs between the magnetite precipitates and the plagioclase host. 
Table 1 CORs of the six most abundant plagioclase-hosted magnetite micro-inclusions in general and specific (main and nucleation) orientation

\begin{tabular}{|c|c|c|c|c|}
\hline Orientation class & Orientation & $\mathrm{mt}<111>$ & $\mathrm{mt}<011>$ & $\mathrm{mt}<001>$ \\
\hline \multirow[t]{3}{*}{$\mathrm{pl}(112) \mathrm{n}-\mathrm{mt}$} & General & $\operatorname{pl}(112) n *$ & & \\
\hline & Specific: main & $\operatorname{pl}(112) n^{*}$ & $\operatorname{pl}(1 \overline{5} 0) n$ & \\
\hline & Specific: nucleation & $\operatorname{pl}(112) n *$ & & $\mathrm{pl}\left[\begin{array}{llll}14 & 10 & 7\end{array}\right]$ \\
\hline \multirow[t]{3}{*}{$\mathrm{pl}(1 \overline{5} 0) \mathrm{n}-\mathrm{mt}$} & General & $\operatorname{pl}(1 \overline{5} 0) n^{*}$ & & \\
\hline & Specific: main & $\operatorname{pl}(1 \overline{5} 0) n^{*}$ & $\mathrm{pl}(112) \mathrm{n}$ & \\
\hline & nucleation & $\operatorname{pl}(1 \overline{5} 0) n^{*}$ & & $\mathrm{pl}\left[\begin{array}{llll}14 & 10 & 7\end{array}\right]$ \\
\hline \multirow[t]{3}{*}{$\mathrm{pl}(\overline{3} 12) \mathrm{n}-\mathrm{mt}$} & General & $\operatorname{pl}(\overline{3} 12) n *$ & & \\
\hline & Specific: main & $\operatorname{pl}(\overline{3} 12) n^{*}$ & $\mathrm{pl}(150) \mathrm{n}$ & \\
\hline & Specific: nucleation & $\operatorname{pl}(\overline{3} 12) n^{*}$ & & $\operatorname{pl}\left[\begin{array}{lll}\overline{14} & 10 & \overline{7}\end{array}\right]$ \\
\hline \multirow[t]{3}{*}{$\mathrm{pl}(150) \mathrm{n}-\mathrm{mt}$} & General & $\operatorname{pl}(150) n^{*}$ & & \\
\hline & Specific: main & $\operatorname{pl}(150) n *$ & $\operatorname{pl}(\overline{3} 12) n$ & \\
\hline & Specific: nucleation & $\operatorname{pl}(150) n *$ & & $\mathrm{pl}\left[\begin{array}{lll}\overline{14} & 10 & \overline{7}\end{array}\right]$ \\
\hline $\mathrm{pl}(100) \mathrm{n}-\mathrm{mt}$ & Specific: nucleation & $\begin{array}{l}\operatorname{pl}(100) n^{*} \text { and } \\
\operatorname{pl}(1 \overline{5} 0) n\end{array}$ & $\mathrm{pl}[001]$ & $\operatorname{pl}\left[\begin{array}{lll}14 & 10 & 7\end{array}\right]$ \\
\hline \multirow[t]{3}{*}{$\mathrm{pl}[001]-\mathrm{mt}$} & General & & $\operatorname{pl}[001]^{*}$ & \\
\hline & Specific: main & $\mathrm{pl}(1 \overline{5} 0) \mathrm{n}$ & $\operatorname{pl}[001]^{*}$ & \\
\hline & Specific: nucleation** & & $\operatorname{pl}[001]^{*}$ & $\mathrm{pl}\left[\begin{array}{lll}14 & 10 & 7\end{array}\right]$ \\
\hline
\end{tabular}

*Directions coinciding with the elongation direction for all orientations of indicated orientation class. Note, for some orientation classes additional specific orientations exist: for the pl(112)n-mt inclusions $\mathrm{mt}<011>/ / \mathrm{pl}[1 \overline{1} 0]$ or $\mathrm{pl}[0 \overline{2} 1]$; for the $\mathrm{pl}(\overline{3} 12) \mathrm{n}-\mathrm{mt}$ inclusions $\mathrm{mt}<011>/ / \mathrm{pl}(112) \mathrm{n}$; for the $\mathrm{pl}(1 \overline{5} 0) \mathrm{n}-\mathrm{mt}$ inclusions $\mathrm{mt}<011>/ / \mathrm{pl}[001]$; for the $\mathrm{pl}[001]$-mt inclusions $\mathrm{mt}<011>/ / \mathrm{pl}(150) \mathrm{n}$ or $\mathrm{pl}(120) \mathrm{n}$

**Suggested CORs

\section{Crystal structure basis for the elongation direction of the magnetite inclusions}

Given that magnetite has cubic symmetry and plagioclase either has monoclinic or triclinic symmetry, the observation of systematic SORs and CORs between the magnetite micro-inclusions and the plagioclase host is puzzling. The systematic orientation relationships can, however, be understood based on similarities between the crystal structures of the two phases. In this context, it is interesting to note that among the plagioclase lattice planes that are parallel to the basal planes of the plane-normal inclusion types and that form the prismatic planes bounding the inclusions parallel to their elongation directions, duplets of pairwise perpendicular or nearly perpendicular lattice planes exist (Table 2). In particular, $\mathrm{pl}(112)$ is nearly perpendicular to $\mathrm{pl}(1 \overline{5} 0)$, and $\mathrm{pl}(\overline{3} 12)$ is nearly perpendicular to $\mathrm{pl}(150)$. In this respect a similarity exists to the magnetite structure, where among the two important lattice planes, $\operatorname{mt}\{111\}$ and $\operatorname{mt}\{011\}$ pairs can be found that are also mutually perpendicular. In addition, the d-spacing of the above-mentioned plagioclase planes is very similar to the d-spacing of $\operatorname{mt}\{222\}$. For example, the $\mathrm{pl}(112)$ and the $\mathrm{pl}(1 \overline{5} 0)$ planes are close to perpendicular to one another, and at room temperature the d-spacing of the two lattice planes is nearly identical, $\mathrm{pl}_{(15 \overline{0})}=2.45 \AA$ and $\mathrm{pl}_{(112)}=2.46 \AA$, so that their traces show nearly cubic symmetry, when projected in the direction of

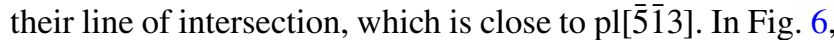
the oxygen atoms of plagioclase and of a $\mathrm{pl}(112) \mathrm{n}-\mathrm{mt}$ inclusion in main orientation are shown in a projection down the $\mathrm{pl}[\overline{5} \overline{1} 3]$ direction. In this projection one of the $\mathrm{mt}\{111\}$ and one of the $\mathrm{mt}\{011\}$ planes are parallel to the viewing direction, and the corresponding oxygen atoms appear as mutually perpendicular rows. For a $\mathrm{pl}(112) \mathrm{n}-\mathrm{mt}$ inclusion in main orientation, one of the $\operatorname{mt}\{111\}$ and one of the $\operatorname{mt}\{011\}$ oxygen layers are parallel to the $\mathrm{pl}(112)$ and the $\mathrm{pl}(1 \overline{5} 0)$ planes, respectively. At room temperature, the d-spacing of the $\mathrm{mt}\{222\}$ planes, $\mathrm{mt}_{(222)}=2.42 \AA$, is nearly identical to the $\mathrm{d}$-spacing of the $\mathrm{pl}(112)$ planes, $\mathrm{pl}_{(112)}=2.46 \AA$, ensuring a good match of the corresponding oxygen layers across the prismatic planes bounding the $\mathrm{pl}(112) \mathrm{n}-\mathrm{mt}$ needles parallel to their elongation direction (Fig. 6a).

The nearly perfect lattice match can also be seen from the coincidence of the respective lattice vectors (Fig. 6c,d). In the projection along the $\mathrm{pl}[\overline{5} \overline{1} 3]$ direction, the $\mathrm{pl}_{(1 \overline{50})}$ and the $\mathrm{pl}_{(112)}$ lattice vectors appear in true length. They enclose an angle of $\sim 90^{\circ}$, and with $\mathrm{pl}_{(150)}=2.45 \AA$ and $\mathrm{pl}_{(112)}=2.46 \AA$ they have nearly the same length leading to a "cubic" symmetry of the oxygen sublattice. For a pl(112)n-mt inclusion, the $\mathrm{mt}_{(2 \overline{2} \overline{2})}$ lattice vector is aligned with and nearly identical to the $\mathrm{pl}_{(112)}$ lattice vector (Fig. $6 \mathrm{~d}, \mathrm{c}$ ), indicating the good match of the lattice planes in the elongation direction of the inclusion. The misfit between the $\mathrm{mt}(111)$ and the $\mathrm{pl}(112)$ oxygen layers on either side of a the prismatic 


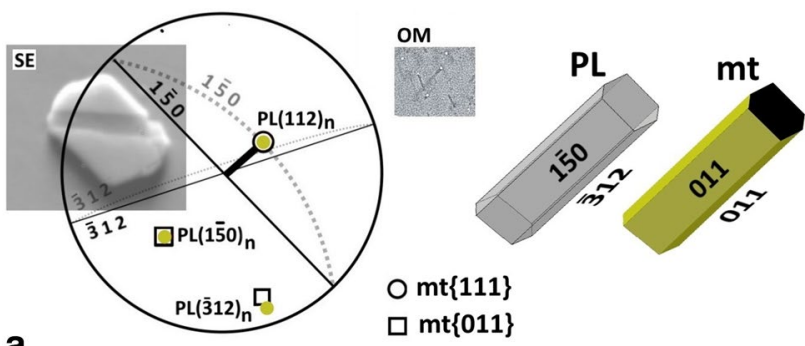

a

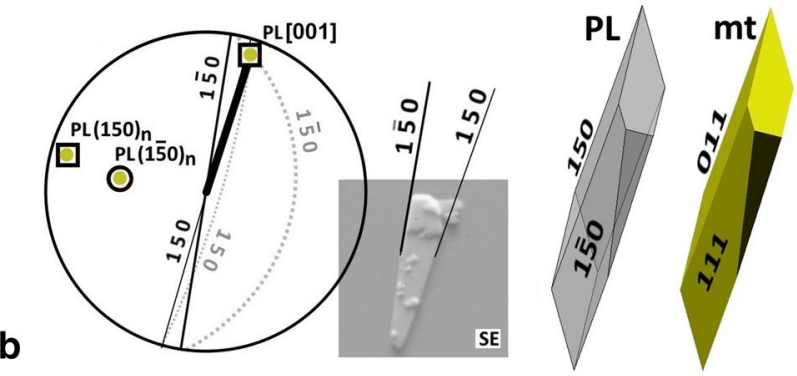

Fig. 5 a Stereographic projections, secondary electron (SE) image and optical image $(\mathrm{OM})$ and reconstructions of the magnetite-plagioclase interface orientations for a $\mathrm{pl}(112) \mathrm{n}-\mathrm{mt}$ needle. b Same representation for a $\mathrm{pl}[001]-\mathrm{mt}$ needle. The dashed lines in the stereographic projections are the great circles corresponding to the indicated plagioclase lattice planes. The corresponding straight thin solid lines represent the traces of these planes on the intersection with the sample surface. The heavy solid lines indicate the needle elongation directions as obtained from U-stage measurements. The poles of the plagioclase planes and directions are marked by yellow circles. The corresponding 3D models with typical facets are shown to the right. The filled black polygons show the cross sections of these needles as they appear on the polished surface of the sample and are thus comparable to the SE images

magnetite-plagioclase interfaces is about $1 \%$. This misfit can either be accommodated by introducing misfit dislocations at every about 100th lattice plane or by elastic deformation of both the inclusion and the host crystals. In any case, due to the good lattice match, the prismatic interfaces likely have low interfacial energy and are thus favored.

For a pl(112)n-mt inclusion in main orientation, one of the $\mathrm{mt}\{011\}$ planes is parallel to the $\mathrm{pl}(1 \overline{50})$ plane, in addition to the parallel alignment of one of the $\operatorname{mt}\{111\}$ planes and the $\mathrm{pl}(112)$ plane. But the d-spacing is rather different for the $\mathrm{mt}\{011\}, \mathrm{mt}_{(011)}=2.97 \AA$, and the $\mathrm{pl}(1 \overline{5} 0)$ planes, $\mathrm{pl}_{(150)}=2.45 \AA$, and there is poor lattice match between the $\{011\}$ oxygen layers of magnetite and the (150) oxygen layers of plagioclase across the basal planes of the inclusions, making them energetically unfavorable so that their formation is suppressed as is actually observed.

Similar structural relationships exist for all shape orientation classes of the plane-normal inclusions. For example, a rotation of the magnetite in Fig. $6 \mathrm{~b}$, d by $90^{\circ}$ around the normal to the image plane (gray dashed arrow) produces a good match between the $\mathrm{pl}(1 \overline{5} 0)$ and one of the $\mathrm{mt}\{111\}$ oxygen layers. This arrangement corresponds to the orientation of the $\mathrm{pl}(1 \overline{5} 0) \mathrm{n}-\mathrm{mt}$ inclusions in main orientation. A similar accordance of the oxygen layers exists for the $\mathrm{pl}(\overline{3} 12) \mathrm{n}-\mathrm{mt}\left(\mathrm{pl}_{\overline{(} \mathbf{3} 12)}=2.50 \AA\right)$, $\mathrm{pl}(150)$ $\mathrm{n}-\mathrm{mt}\left(\mathrm{pl}_{(150)}=2.40 \AA\right)$ and $\mathrm{pl}(100) \mathrm{n}-\mathrm{mt}\left(\mathrm{pl}_{(300)}=2.45 \AA\right)$ inclusions.

From these structural relationships we infer that the SORs and CORs of the magnetite micro-inclusions of the plane-normal type result from the alignment of the densely packed $m t\{111\}$ oxygen layers with the oxygen layers in the plagioclase that are parallel to the $\mathrm{pl}(112), \mathrm{pl}(\overline{3} 12)$, $\mathrm{pl}(1 \overline{50}), \mathrm{pl}(150)$, and the $\mathrm{pl}(100)$ planes, depending on the shape orientation class. The d-spacing of these oxygen layers is very similar to the d-spacing of the $\mathrm{mt}\{222\}$ oxygen layers. As a consequence, the oxygen sublattices of magnetite and plagioclase show a good match across interfaces running perpendicular to these plagioclase planes, which necessarily are interfaces containing the elongation directions of the plane-normal magnetite micro-inclusions. For the inclusions in main orientation, the prismatic interfaces bounding the inclusions in their elongation direction are aligned parallel to the $\mathrm{mt}\{011\}$ and a second important oxygen layer in plagioclase. This orientational coincidence is considered as a secondary effect further contributing to minimizing the interfacial energy, which discriminates
Table 2 Angles between magnetite and plagioclase lattice planes

\begin{tabular}{lllllll}
\hline & $\operatorname{mt}\{111\}$ & $\operatorname{pl}(112)$ & $\operatorname{pl}(1 \overline{5} 0)$ & $\operatorname{pl}(\overline{3} 12)$ & $\operatorname{pl}(150)$ & $\operatorname{pl}(001)$ \\
\hline $\operatorname{mt}\{011\}$ & $90^{\circ}, 35^{\circ}$ & & & & & \\
$\operatorname{pl}(112)$ & & - & $\mathbf{8 8}^{\circ}\left(\mathbf{9 1}^{\circ}\right)$ & $85^{\circ}\left(85^{\circ}\right)$ & $66^{\circ}\left(62^{\circ}\right)$ & $45^{\circ}\left(46^{\circ}\right)$ \\
$\operatorname{pl}(1 \overline{5} 0)$ & & $\mathbf{8 8}^{\circ}\left(\mathbf{9 1}^{\circ}\right)$ & - & $66^{\circ}\left(65^{\circ}\right)$ & $38^{\circ}\left(39^{\circ}\right)$ & $\mathbf{9 0}^{\circ}\left(\mathbf{9 0}^{\circ}\right)$ \\
$\operatorname{pl}(\overline{3} 12)$ & & $85^{\circ}\left(85^{\circ}\right)$ & $66^{\circ}\left(65^{\circ}\right)$ & - & $\mathbf{9 2}^{\circ}\left(\mathbf{9 1}^{\circ}\right)$ & $45^{\circ}\left(45^{\circ}\right)$ \\
$\operatorname{pl}(150)$ & & $66^{\circ}\left(62^{\circ}\right)$ & $38^{\circ}\left(39^{\circ}\right)$ & $\mathbf{9 2}^{\circ}\left(\mathbf{9 1}^{\circ}\right)$ & - & $\mathbf{9 0}^{\circ}\left(\mathbf{9 0}^{\circ}\right)$ \\
\hline
\end{tabular}

Entries in bold font indicate pairwise perpendicular lattice planes corresponding to prismatic planes bounding the magnetite inclusions in main orientation parallel to their elongation directions

The angles are given for monoclinic high albite (Winter et al. 1979), the angles for triclinic labradorite (Wenk et al. 1980) are given in brackets 
Fig. 6 a Structure model of the oxygen (red circles) sublattices of plagioclase and magnetite for a pl(112)n-mt inclusion in main orientation viewed down the $\mathrm{pl}[\overline{5} \overline{1} 3]$ direction. $\mathbf{b}$ : Oxygen sublattice of magnetite in same orientation and projection as in $\mathbf{a}$, the viewing direction is indicated in Fig. 3a. The magnetite and the plagioclase lattices are aligned with one of the $\mathrm{mt}\{011\}$ planes parallel to $\operatorname{pl}(150)$ and one of the $\operatorname{mt}\{111\}$ planes parallel to $\mathrm{pl}(112)$. c, $\mathbf{d}$ : Simulated diffraction patterns for the projections shown in figures $a$ and $b$. The dashed gray arrow in figure $\mathbf{d}$ indicates a rotation of the magnetite in $\mathbf{b}$ and $\mathbf{d}$ by $90^{\circ}$ around the normal to the image plane, which leads to the main orientation of the $\mathrm{pl}(1 \overline{5} 0) \mathrm{n}-\mathrm{mt}$ inclusions. The coincidence of plagioclase and magnetite planes in the simulated diffraction patterns (c) for the $\mathrm{pl}(112) \mathrm{n}-\mathrm{mt}$ and the $\mathrm{pl}(1 \overline{5} 0$ )n-mt inclusions is marked by red and dashed gray circles, respectively

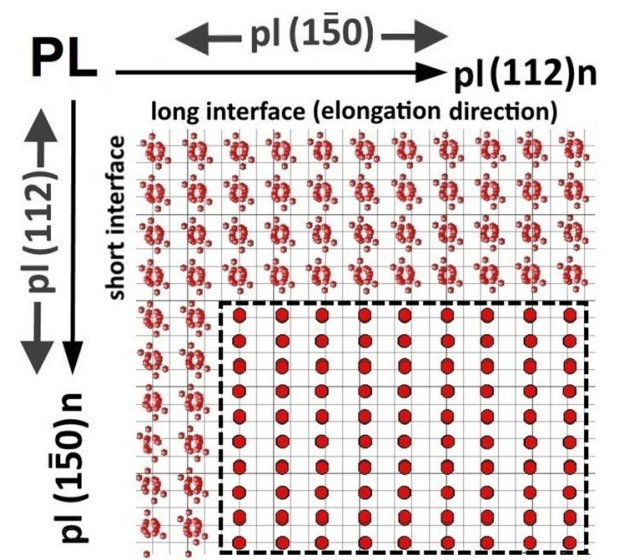

a

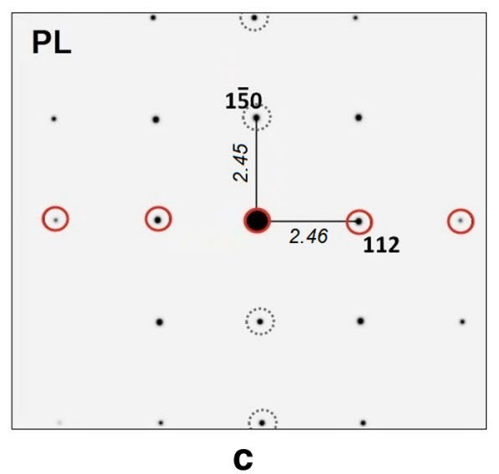

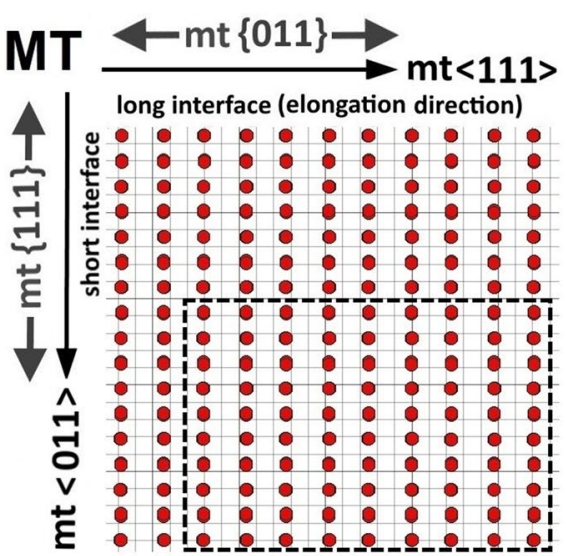

b

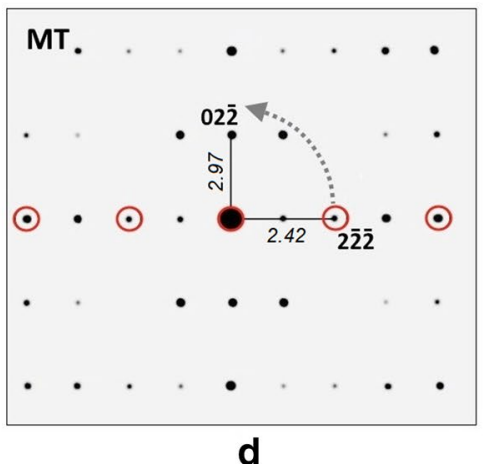

between the general and the main orientations of the plane-normal inclusions.

\section{Oriented nucleation of the magnetite inclusions}

The crystal structure of plagioclase is usually rationalized based on crankshaft-like chains running parallel to the pl[100]-direction that comprise interconnected fourmembered rings of $\mathrm{SiO}_{4}$ and $\mathrm{AlO}_{4}$ tetrahedra (Ribbe 1984). In their study on plagioclase-hosted magnetite micro-inclusions, Wenk et al. (2011) pointed out that in the context of plagioclase-hosted magnetite, micro-inclusions channels in the plagioclase structure that are formed by six-membered rings of $\mathrm{SiO}_{4}$ and $\mathrm{AlO}_{4}$ tetrahedra and run parallel to the pl[001] direction are of interest. It was shown by Wenk et al. (2011) that these channels are prone to accommodate $\mathrm{FeO}_{6}$ octahedra, which are an important element of the crystal structure of magnetite. It was argued that the edges of the $\mathrm{SiO}_{4}$ and $\mathrm{AlO}_{4}$ tetrahedra forming the channels provide preferred sites for nucleation and growth of magnetite needles parallel to the $\mathrm{pl}[001]$ direction. Following the reasoning of Wenk et al. (2011), we explore the crystallographic basis of the preferred nucleation of magnetite in these channels and extend the concept to the plane-normal inclusion types. To account for the possibility that the magnetite micro-inclusions originally formed in a monoclinic plagioclase, which went through the monoclinic-triclinic transition after the formation of the magnetite micro-inclusions, we use the crystal structure of monoclinic high albite (Winter et al. 1979) and of triclinic labradorite (Wenk et al. 1980).

In Fig. 7, the six-membered rings of $\mathrm{SiO}_{4}$ and $\mathrm{AlO}_{4}$ tetrahedra forming the channels parallel to the pl[001] direction in the plagioclase structure are shown schematically in a projection down the pl[001] direction. The distance between the $\mathrm{Od}$ and $\mathrm{Ob}$ oxygen atoms connecting the $\mathrm{SiO}_{4}-\mathrm{AlO}_{4}$ tetrahedra in the six-membered rings is $4.34 \AA$ in high albite (based on Winter et al. 1979) and 4.26 $\AA$ and $4.23 \AA$ in labradorite (based on Wenk et al. 1980). This distance is very similar to the distance between the two oxygen atoms in the $\mathrm{O}_{1}-\mathrm{Fe}_{1}-\mathrm{O}_{1}$ arrangement of the $\mathrm{FeO}_{6}$ octahedra of magnetite, which is $4.28 \AA$ (based on Fleet 1986). The $\mathrm{FeO}_{6}$ octahedra can thus be easily accommodated in the channels by sharing the $\mathrm{Od}$ and $\mathrm{Ob}$ oxygen atoms of the tetrahedral rings with the $\mathrm{O}_{1}$ atoms of the $\mathrm{FeO}_{6}$ octahedra. In each sixmembered tetrahedral ring, there are two pairs of Od and Ob oxygen atoms, which are aligned with the pl[14 10 7] and with the $\mathrm{pl}[\overline{1} \overline{4} 10 \overline{7}]$ directions, respectively. Noting that the line defined by the $\mathrm{O}_{1}-\mathrm{Fe}_{1}-\mathrm{O}_{1}$ arrangement in the $\mathrm{FeO}_{6}$ octahedra is parallel to one of the $\mathrm{mt}<001>$ directions (Fig. 7b), the $\mathrm{FeO}_{6}$ octahedra of magnetite can thus be accommodated in the plagioclase structure so that one 


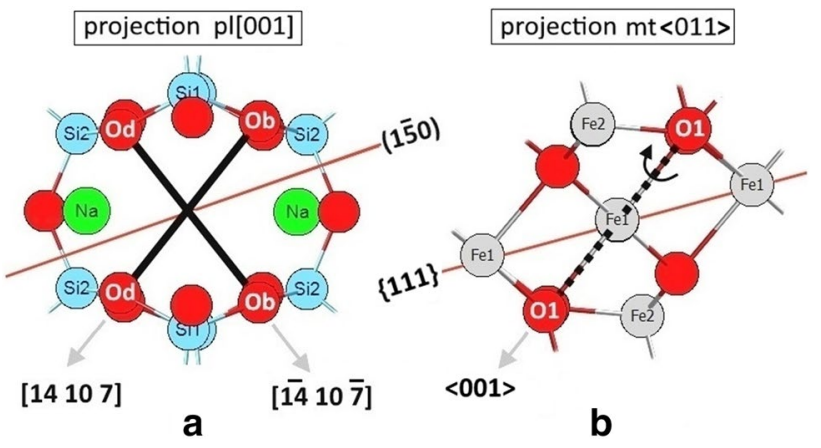

Fig. 7 a Projection of the plagioclase structure down its [001] direction showing a six-membered $\mathrm{SiO}_{4}-\mathrm{AlO}_{4}$ tetrahedral ring (crystal structural data of high albite from: Winter et al. 1979). b Projection of the magnetite structure down its $<011>$ direction (crystal structural data from: Fleet 1986). The black solid and dashed lines connect the oxygen atoms that are shared by both minerals in case of accommodation of magnetite $\mathrm{FeO}_{6}$ octahedra in the six-membered $\mathrm{SiO}_{4}-\mathrm{AlO}_{4}$ tetrahedral rings of the plagioclase structure. The heavy red lines are the traces of the $\mathrm{pl}(1 \overline{50})$ and of one of the $\operatorname{mt}\{111\}$ planes, which are oriented parallel to the viewing direction. Here, the line connecting the $\mathrm{O}_{1}-\mathrm{Fe}_{1}-\mathrm{O}_{1}$ positions is aligned with the $\mathrm{mt}[001]$ direction and with the line connecting the $\mathrm{Od}-\mathrm{Ob}$ positions that is parallel to the pl[14 10 7] direction. This arrangement corresponds to the $\mathrm{pl}(100) \mathrm{n}-\mathrm{mt}$ inclusions, where one of the $\mathrm{mt}<011>$ directions is parallel to $\mathrm{pl}[001]$ and one of the $\mathrm{mt}\{111\}$ planes is parallel to $\mathrm{pl}(1 \overline{5} 0)$. It is also compatible with the general rule for the formation of $\mathrm{pl}(1 \overline{5} 0) \mathrm{n}-\mathrm{mt}$ inclusions, where one of the $\mathrm{mt}\{111\}$ planes is parallel to $\mathrm{pl}(1 \overline{5} 0)$. It does not, however, correspond to the main orientation of the $\mathrm{pl}(150) \mathrm{n}-\mathrm{mt}$ inclusions, where one of the $\mathrm{mt}\{011\}$ planes is required to be parallel to $\mathrm{pl}(112)$ in addition. The curved arrow indicates the rotational degree of freedom of the $\mathrm{FeO}_{6}$ octahedron of magnetite. In the triclinic labradorite lattice the directions pl[14 10 7] and $\mathrm{pl}[\overline{14} 10 \overline{7}]$ deviate from the $\mathrm{Od}-\mathrm{Ob}$ connection lines by an angle of $\sim 5-6^{\circ}$

of the $\mathrm{mt}<001>$ directions is either parallel to the $\mathrm{pl}[1410$ 7] direction or to the $\mathrm{pl}[\overline{1} \overline{4} 10 \overline{7}]$ direction. Given the coincidence of the two $\mathrm{O}_{1}$ oxygen atoms of the $\mathrm{FeO}_{6}$ octahedron with the $\mathrm{Od}$ and $\mathrm{Ob}$ oxygen atoms of the tetrahedral rings, the $\mathrm{FeO}_{6}$ octahedron has one rotational degree of freedom around the $\mathrm{O}_{1}-\mathrm{Fe}_{1}-\mathrm{O}_{1}$ axis and thus around one of the $\mathrm{mt}<001>$ directions (Fig. 7b).

Figure 7 shows the case where the $\mathrm{O}_{1}-\mathrm{Fe}_{1}-\mathrm{O}_{1}$ arrangement of the $\mathrm{FeO}_{6}$ octahedron is parallel to the $\mathrm{pl}\left[\begin{array}{ll}14 & 10\end{array}\right]$ direction. Making use of the free rotation of the $\mathrm{FeO}_{6}$ octahedron around the $\mathrm{mt}[001]$ direction, an orientation can be found so that one of the $\mathrm{mt}\{111\}$ planes is nearly parallel to $\mathrm{pl}(1 \overline{5} 0)$, which corresponds to the CORs of the $\mathrm{pl}(100) \mathrm{n}-\mathrm{mt}$ and the $\mathrm{pl}(1 \overline{5} 0) \mathrm{n}-\mathrm{mt}$ inclusions. Applying a different rotation angle around the same rotation axis, a second orientation of the magnetite $\mathrm{FeO}_{6}$ octahedron can be found, where one of the $\mathrm{mt}\{111\}$ planes is parallel to the $\mathrm{pl}(112)$ plane, which corresponds to the COR of the pl(112)n-mt inclusions. Similarly, when the $\mathrm{O}_{1}-\mathrm{Fe}_{1}-\mathrm{O}_{1}$ arrangement of the $\mathrm{FeO}_{6}$ octahedron of magnetite is aligned with the pl[1ㅅ $10 \overline{7}]$ direction, two orientation relationships may be produced by rotation of the $\mathrm{FeO}_{6}$ octahedron around the $\mathrm{mt}[001]$ direction, which correspond to the orientations of the $\mathrm{pl}(\overline{3} 12) \mathrm{n}-\mathrm{mt}$ and the $\mathrm{pl}(150) \mathrm{n}-\mathrm{mt}$ inclusions, where one of the $\mathrm{mt}\{111\}$ planes is parallel to the $\mathrm{pl}(\overline{3} 12)$ and to the $\mathrm{pl}(150)$ planes, respectively.

The shape orientation classes $\mathrm{pl}(112) \mathrm{n}-\mathrm{mt}, \mathrm{pl}(\overline{3} 12) \mathrm{n}-\mathrm{mt}$, $\mathrm{pl}(1 \overline{5} 0) \mathrm{n}-\mathrm{mt}, \mathrm{pl}(150) \mathrm{n}-\mathrm{mt}$, and $\mathrm{pl}(100) \mathrm{n}-\mathrm{mt}$ of the plane-normal inclusions are linked with the four orientation variants of the $\mathrm{FeO}_{6}$ octahedra of magnetite in the six-membered tetrahedral rings shown in a projection down the pl[001] direction in Fig. 8. It should be noted that besides the pairs of suitably spaced oxygen atoms defining the pl[14 10 7] and $\mathrm{pl}[\overline{14} 10 \overline{7}]$ directions, other pairs of oxygen atoms pertaining to the six-membered rings of $\mathrm{SiO}_{4}$ and $\mathrm{AlO}_{4}$ tetrahedra forming the channels parallel to plagioclase [001] exist, which have suitable distances between the oxygen atoms (4.10-4.40 $\AA$ ) for accommodating magnetite $\mathrm{FeO}_{6}$ octahedra in the plagioclase structure. These pairs of oxygen atoms define several additional directions including $\mathrm{pl}\left[\begin{array}{ll}0 & 2\end{array}\right], \mathrm{pl}[0 \overline{2} 3], \mathrm{pl}[4 \overline{6} 9]$, and $\mathrm{pl}[\overline{9} 20]$, which one of the $\mathrm{mt}<001>$ directions could be aligned to. But only those orientation variants that allow for the parallel alignment of important oxygen layers in plagioclase and magnetite were identified in the CORs of the needle-shaped (elongated) magnetite micro-inclusions. We infer that out of the numerous suitable nucleation orientations only those that are accompanied by parallel alignment of oxygen layers and $\mathrm{d}$-spacing match form needles. If the alignment and match do not apply, the magnetite crystals attain an isometric shape and form dust-like micro-inclusions.

For the pl[001]-mt inclusions, one of the $\mathrm{mt}<011>$ directions is parallel to the needle elongation direction. Their elongation direction cannot be argued based on good match of oxygen layers between the magnetite inclusions and the plagioclase host. According to Wenk et al. (2011), formation of the pl[001]-mt inclusions should rather be ascribed to the high concentration of nucleation sites along the pl[001] channels and the supposed enhanced diffusion along these channels, which both foster the formation of magnetite needles parallel to the $\mathrm{pl}[001]$ direction. It was first described by Sobolev (1990) and is confirmed by our observations that the pl[001]-mt inclusions are generally thicker and shorter than the inclusions pertaining to the other orientation classes. Moreover, whereas both the pl[001]-mt inclusions and all types of the plane-normal inclusions are observed in plagioclase of labradorite to bytownite compositions with anorthite contents of $50-70 \mathrm{~mol} \%$, the pl[001]-mt inclusions are also observed in plagioclase of oligoclase to andesine compositions with anorthite contents of 30-40 mol \% in which no other types of micro-inclusions are found. It is inferred that the $\mathrm{pl}[001]-\mathrm{mt}$ inclusions form by another mechanism than 

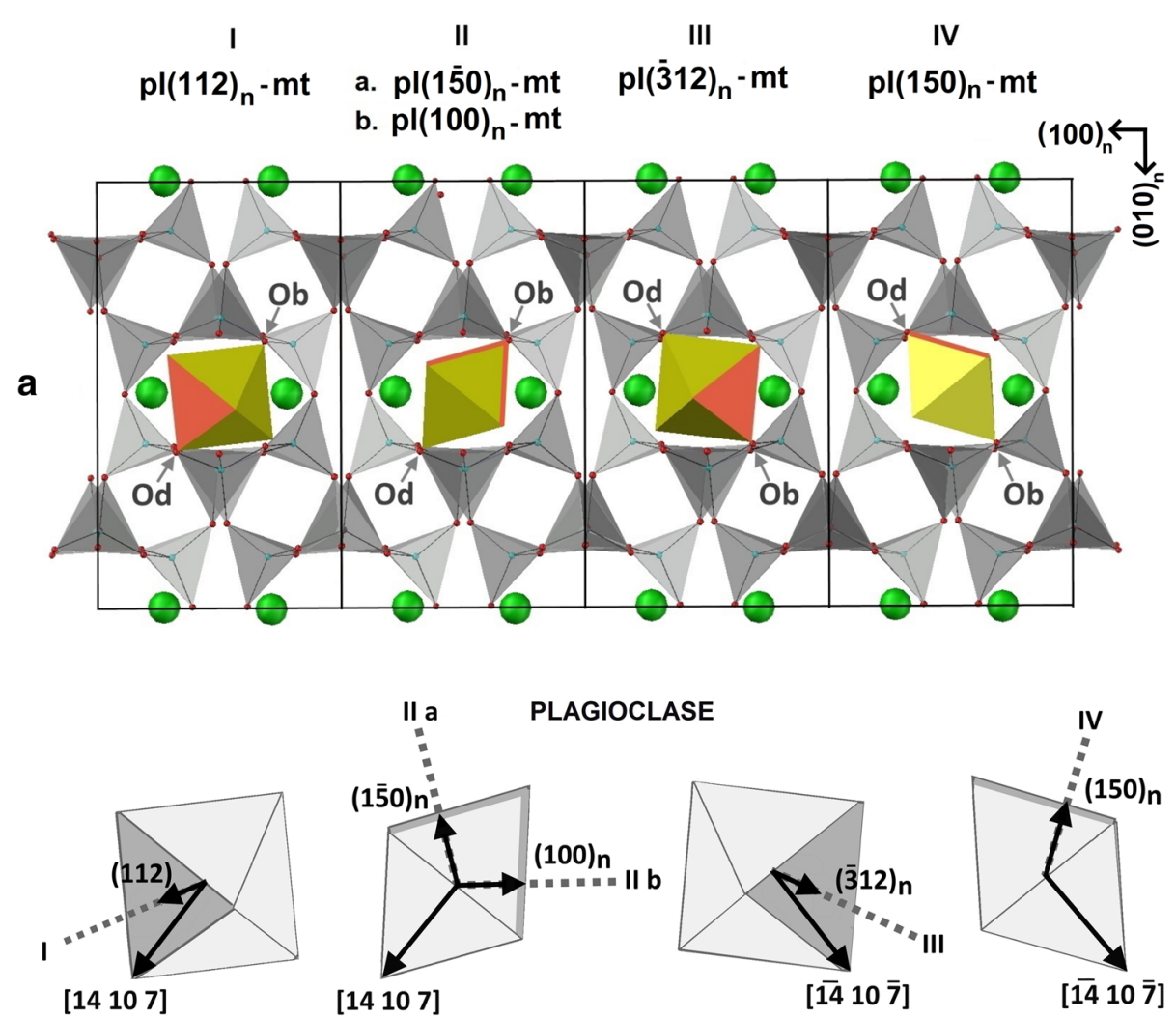

MAGNETITE

b

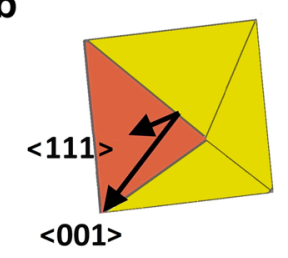

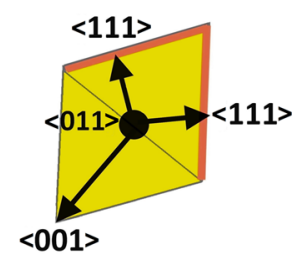

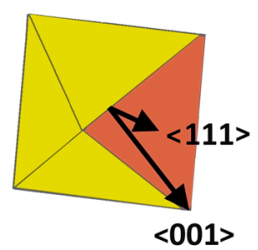

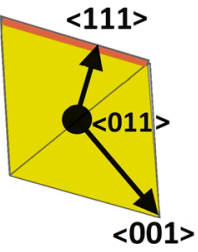

Fig. 8 a Structural model of high albite (Winter et al. 1979) in [001]-projection showing the six-membered rings of $\mathrm{SiO}_{4}$ and $\mathrm{AlO}_{4}$ tetrahedra forming the channels parallel to the pl[001] direction. Magnetite $\mathrm{FeO}_{6}$ octahedra (yellow polyhedra) are accommodated in the channels in four different orientation variants. The Od and $\mathrm{Ob}$ oxygen positions that are shared between the plagioclase and the $\mathrm{FeO}_{6}$ octahedra are marked by gray arrows. The planes that are aligned in the magnetite and plagioclase structures are colored in red. The orientation variants of the $\mathrm{FeO}_{6}$ octahedra are in accordance with the CORs between the pl(112)n-mt, pl(150)n-mt, pl(100)n-mt, $\mathrm{pl}(\overline{3} 12) \mathrm{n}-\mathrm{mt}$, and $\mathrm{pl}(150) \mathrm{n}-\mathrm{mt}$ inclusions and the plagioclase host. b

the inclusions of the plane-normal type, and they occur over a larger range of conditions.

Finally, the question arises, how the main crystallographic orientations of the micro-inclusions relate to the orientation of the $\mathrm{FeO}_{6}$ octahedra in the plagioclase structure. The orientations of the $\mathrm{FeO}_{6}$ octahedra where the two $\mathrm{O}_{1}$ atoms of the $\mathrm{O}_{1}-\mathrm{Fe}_{1}-\mathrm{O}_{1}$ arrangement are shared with the $\mathrm{Ob}$ and $\mathrm{Od}$ oxygen atoms of the six-membered tetrahedral rings and one of the $\mathrm{mt}\{111\}$ planes is parallel to $\mathrm{pl}(112), \operatorname{pl}(1 \overline{5} 0), \operatorname{pl}(\overline{3} 12)$, $\mathrm{pl}(150)$, or $\mathrm{pl}(100)$ are the respective nucleation orientations
$\mathrm{FeO}_{6}$ octahedra and corresponding plagioclase lattice planes for the four orientation variants. In orientation variant $\mathrm{I}$, one of the $\operatorname{mt}\{111\}$ planes is parallel to the $\mathrm{pl}(112)$ plane; in orientation variant II, one of the $\mathrm{mt}\{111\}$ planes is parallel to the $\mathrm{pl}(1 \overline{5} 0)$ plane and another one of the $\mathrm{mt}\{111\}$ planes is parallel to the $\mathrm{pl}(100)$ plane; in orientation variant III, one of the $\mathrm{mt}\{111\}$ planes is parallel to the $\mathrm{pl}(\overline{3} 12)$ plane; and in orientation variant IV, one of the $\mathrm{mt}\{111\}$ planes is parallel to the $\mathrm{pl}(150)$ plane. The elongation directions of the micro-inclusions are indicated by the dashed gray lines, and the small arrows indicate the corresponding plane-normal directions

of the $\mathrm{pl}(112) n-m t$, the $\mathrm{pl}(1 \overline{5} 0) \mathrm{n}-\mathrm{mt}$, the $\mathrm{pl}(\overline{3} 12) \mathrm{n}-\mathrm{mt}$, the $\mathrm{pl}(150) \mathrm{n}-\mathrm{mt}$, and the $\mathrm{pl}(100) \mathrm{n}-\mathrm{mt}$ inclusions. Starting from the nucleation orientations the corresponding main orientations cannot be reached by applying the rotational degree of freedom around the $\mathrm{mt}[001]$ direction that is allowed by the coincidence of the $\mathrm{O}_{1}$ atoms of the $\mathrm{FeO}_{6}$ octahedra with the $\mathrm{Ob}$ and $\mathrm{Od}$ oxygen atoms of the tetrahedral rings. The main orientations can only be reached by rotation around the mt[111], which preserves the parallel alignment of the densely packed $\mathrm{mt}\{111\}$ oxygen layers with the respective 
oxygen layers in the plagioclase. The latter is considered as the prime control of the SOR and COR of the plane-normal inclusions.

For example, the main orientation of the pl(112)n-mt inclusions is characterized by one of the $\mathrm{mt}\{111\}$ planes being parallel to the $\mathrm{pl}(112)$ plane and one of the $\operatorname{mt}\{011\}$ planes being parallel to the $\mathrm{pl}(1 \overline{5} 0)$ plane. This COR can be reached from the nucleation orientation by a rotation of about $15^{\circ}$ around the $\mathrm{mt}<111>$ direction that is perpendicular to $\mathrm{pl}(112)$. The $\mathrm{pl}(112) \mathrm{n}-\mathrm{mt}$ inclusions show indeed a rotational dispersion of their COR corresponding to this rotation (Ageeva et al. 2016). Similarly a statistical COR corresponding to a rotation around the $\mathrm{pl}(1 \overline{5} 0) \mathrm{n}$ direction was shown for the $\mathrm{pl}(1 \overline{5} 0) \mathrm{n}-\mathrm{mt}$ inclusions by the same authors. It must be noted that the coincidence of the $\mathrm{O}_{1}$ atoms of the $\mathrm{FeO}_{6}$ octahedra with the $\mathrm{Ob}$ and $\mathrm{Od}$ oxygen atoms of the tetrahedral rings, which is ensured in the nucleation orientation, is incompatible with a rotation around any one of the $\mathrm{mt}<111>$ directions and is thus lost for any other general orientation and for the main orientation. In Fig. 9, the rotation from the nucleation orientation to the main orientation is shown for a pl(112)n-mt inclusion.

The $\mathrm{pl}(100) \mathrm{n}-\mathrm{mt}$ inclusions represent a particular case, because besides the match of the d-spacing match and alignment of the oxygen layers in elongation direction, these inclusions show parallel orientation of one of the $\operatorname{mt}\{111\}$ with $\mathrm{pl}(1 \overline{5} 0)$ providing an additional alignment of oxygen layers exactly in the position of nucleation (Fig. 4a, left). No rotation around the needle elongation direction was found for the micro-inclusions of this orientation class.
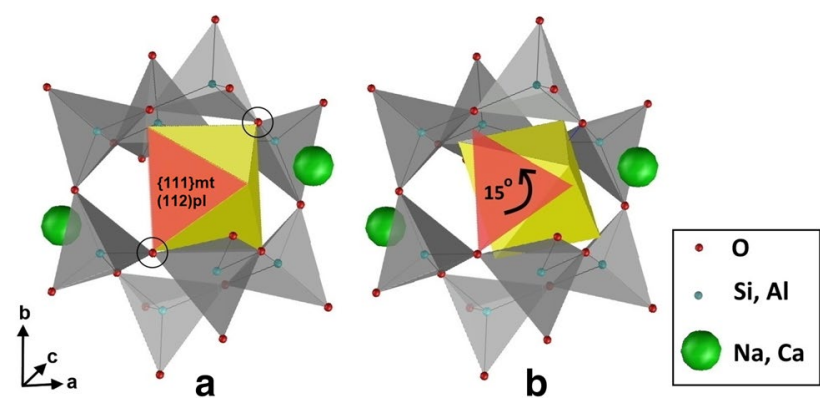

Fig. 9 Orientation of the $\mathrm{FeO}_{6}$-octahedron (yellow) in a six-membered ring of $\mathrm{SiO}_{4}$ and $\mathrm{AlO}_{4}$ tetrahedra (grey) in a projection that ensures that $\mathrm{mt}\{111\}$ and $\mathrm{pl}(112)$ are parallel to the plane of view. a Nucleation orientation of the $\mathrm{FeO}_{6}$-octahedron in orientation variant I corresponding to the $\mathrm{pl}(112) \mathrm{n}-\mathrm{mt}$ inclusions. b Orientation of the $\mathrm{FeO}_{6}$-octahedra after $15^{\circ}$ rotation around the normal to the $\mathrm{pl}(112)$ plane into the main orientation of the pl(112)n-mt needles with one of the $\mathrm{mt}\{111\}$ planes parallel to the $\mathrm{pl}(112)$ and one of the $\mathrm{mt}\{011\}$ planes parallel to the $\mathrm{pl}(1 \overline{50})$. The red triangle (in both images) represents the $\mathrm{pl}(112)$ plane

\section{Processes underlying the formation of oriented magnetite inclusions in plagioclase}

The typical order of crystallization of oceanic gabbro is olivine $\rightarrow$ plagioclase $\rightarrow$ clinopyroxene $\rightarrow$ orthopyroxene as expected for the crystallization sequence of MORB-type melt at low pressure (e.g., Villiger et al. 2007; Suhr et al. 2008). In drilled sections of oceanic gabbro, indeed the corresponding sequence from olivine-rich depleted lithologies to gabbro and gabbronorite and finally to highly evolved oxide gabbros enriched in incompatible elements (Godard et al. 2009; Dick et al. 2017, 2019) is observed. Plagioclasehosted $\mathrm{Fe}-\mathrm{Ti}$ oxide micro-inclusions are common in both, highly evolved oxide gabbros and gabbros without cumulus or intercumulus oxide grains. They are typical in middleto coarse-grained gabbro and usually occur in the central portions of big plagioclase grains and are less frequent or missing in the rims. These features suggest that three factors underlay the appearance of magnetite micro-inclusions in plagioclase of oceanic gabbros: (i) early crystallization of plagioclase, preceding the appearance of pyroxene and individual $\mathrm{Fe}-\mathrm{Ti}$ oxides grains in the matrix. This implies high concentration of $\mathrm{Fe}$ in the melt and crystallization of relatively Fe-rich plagioclase; (ii) increase of $f \mathrm{O}_{2}$ providing oxygen supply required for the nucleation of $\mathrm{Fe}-\mathrm{Ti}$ oxides in the plagioclase host; such conditions may accompany an enrichment of plagioclase by iron (under magmatic or sub-solidus conditions), or contribute to the precipitation of $\mathrm{Fe}-\mathrm{Ti}$ oxides from relatively $\mathrm{Fe}$-rich plagioclase during cooling; (iii) slow cooling providing the time needed for nucleation and growth of the micro-inclusions.

Neither the mechanism nor the exact temperature of precipitation is known, and it is uncertain whether the magnetite precipitates have formed in a monoclinic or in a triclinic structure. In paleomagnetic studies (Ebert et al. 2010; Evans et al. 1968; Sobolev and Faynberg 1990; Feinberg et al. 2005; Biedermann et al. 2016; Calvín et al. 2017), it is generally found that magnetite inclusions in the rock forming silicate minerals carry a very stable primary thermoremanence indicating that the magnetite needles formed by high-temperature exsolution above the Curie temperature of $580{ }^{\circ} \mathrm{C}$ of magnetite (Ebert et al. 2010). Once the plagioclase has become supersaturated with respect to magnetite, this mineral nucleated in the channels running parallel to $\mathrm{pl}[001]$ of the plagioclase structure. Oriented nucleation of magnetite was favored by the perfect match between the oxygen atoms pertaining to the $\mathrm{FeO}_{6}$ octahedra of the magnetite structure and specific oxygen atoms of the six-membered tetrahedral rings forming the channels in the plagioclase structure. The ideal nucleation orientation with one of the $\mathrm{mt}\{001\}$ directions parallel or closely parallel to pl[14 10 7] or $\mathrm{pl}[\overline{14} 10 \overline{7}]$ allows for the parallel alignment of one of the densely packed $\mathrm{mt}\{111\}$ oxygen layers with oxygen layers 
in plagioclase that are parallel to $\mathrm{pl}(112), \mathrm{pl}(1 \overline{5} 0), \mathrm{pl}(\overline{3} 12)$, $\mathrm{pl}(150)$ and $\mathrm{pl}(100)$. The nucleation orientation does not, however, allow for the additional parallel alignment of one of the $\mathrm{mt}\{011\}$ oxygen layers with another one of the important oxygen layers in the plagioclase host. The alignment of a second oxygen layer drives rotation around the $\mathrm{mt}[111]$ direction, which is parallel to the needle elongation direction, towards or into the main orientation. It is not known whether this rotation is linked to recrystallization or is a primary feature that was already attained during nucleation.

Formation of the magnetite inclusions with their elongation direction parallel to the $\mathrm{pl}[001]$ direction cannot be rationalized based on the alignment of important oxygen layers in magnetite and plagioclase. Following Wenk et al. (2011), their formation is ascribed to the presence of abundant magnetite nucleation sites along the channels running parallel to the pl[001] direction. In addition, growth of magnetite inclusions parallel to $\mathrm{pl}[001]$ is enhanced by the supposed fast diffusion along these channels.

\section{Conclusions}

Plagioclase from anorthosites and gabbros often contain needle- or lath-shaped magnetite micro-inclusions with clear shape orientation following several well-defined directions in the plagioclase host. The shape orientation relationships are accompanied by systematic crystallographic orientation relationships. The links between the shape- and crystallographic orientation relationships can be understood based on the dimensional and angular match between the magnetite and plagioclase crystal structures. In the studied plagioclase crystals, $90 \%$ of the magnetite micro-inclusions pertain to six-shape orientation classes. One orientation class has its elongation direction and one of the $\mathrm{mt}<011>$ directions parallel to the pl[001] direction, and the other five orientation classes are of the plane-normal type, in which inclusion elongation direction coincides with one of the $\mathrm{mt}<111>$ directions and with either the $\mathrm{pl}(112)$, the $\mathrm{pl}(1 \overline{5} 0)$, the $\mathrm{pl}(\overline{3} 12)$, the $\mathrm{pl}(150)$, or the $\mathrm{pl}(100)$ plane normal, respectively. The preferred direction of growth (shape orientation) is determined by the alignment of the close-packed $\mathrm{mt}<111>$ oxygen layers with the corresponding oxygen layers in plagioclase, which have nearly identical $\mathrm{d}$-spacing. These orientation relations may be traced back to the nucleation stage, where $\mathrm{FeO}_{6}$ octahedra of the magnetite crystal structure are accommodated in an oriented manner in channels running parallel to $\mathrm{pl}[001]$ in the plagioclase structure.

The magnetite inclusions with their elongation direction parallel to the pl[001] direction do not follow the same pattern of lattice match as the plane-normal types. These inclusions rather reflect the availability of abundant magnetite nucleation sites in the channels parallel to the pl[001] direction.

In many gabbros and anorthosites magnetite micro-inclusions pertaining to different orientation classes are present within the plagioclase crystals. The magnetite micro-inclusions are often the main carriers of the natural magnetic remanence and endow their diamagnetic plagioclase host with a magnetic moment. In view of the magnetocrystalline anisotropy of magnetite, understanding the systematics of the shape and crystallographic orientation relationships of magnetite micro-inclusions in plagioclase is highly relevant for interpreting paleomagnetic data, in particular, when single grain measurements are made.

Acknowledgements This study was funded by the Austrian Science Foundation (FWF) grant Nr. I 3998-N29 and Russian Foundation for Basic Research (RFBR) grant Nr. 18-55-14003. The authors are grateful to Roman Schuster for consultations and assistance on the MTEX processing of EBSD data and to Thomas Griffiths and Oksana Karimova for fruitful discussion. The constructive reviews by Florian Heidelbach and an anonymous reviewer are gratefully acknowledged.

Funding Open access funding provided by Austrian Science Fund (FWF).

Open Access This article is licensed under a Creative Commons Attribution 4.0 International License, which permits use, sharing, adaptation, distribution and reproduction in any medium or format, as long as you give appropriate credit to the original author(s) and the source, provide a link to the Creative Commons licence, and indicate if changes were made. The images or other third party material in this article are included in the article's Creative Commons licence, unless indicated otherwise in a credit line to the material. If material is not included in the article's Creative Commons licence and your intended use is not permitted by statutory regulation or exceeds the permitted use, you will need to obtain permission directly from the copyright holder. To view a copy of this licence, visit http://creativecommons.org/licenses/by/4.0/.

\section{References}

Ageeva O, Habler G, Topa D, Waitz T, Li C, Pertsev A, Zhilicheva O, Abart R (2016) Plagioclase hosted Fe-Ti-oxide micro-inclusions in an oceanic gabbro-plagiogranite association from the Mid Atlantic Ridge at $13^{\circ} 34^{\prime}$ N. Am Journ Sci 316:85-109

Ageeva O, Habler G, Pertsev A, Abart R (2017) Fe-Ti oxide microinclusions in clinopyroxene of oceanic gabbro: phase content, orientation relations and petrogenetic implication. Lithos 290-291:104-115

Andersen O (1915) On aventurine feldspar. Am J Sci 238:351-399

Aranovich LY, Prokofiev VY, Pertsev AN, Bortnikov NS, Ageeva OA, Bel'tenev VE, Simakin, SG, (2015) Composition and origin of a $\mathrm{K}_{2} \mathrm{O}$ rich granite melt in the mid atlantic ridge, $1334^{\prime} \mathrm{N}$ : evidence from the analysis of melt inclusions and minerals of the gabbroplagiogranite association. Dokl Earth Sci 460(2):174-178

Armbrustmacher TJ, Banks NG (1974) Clouded plagioclase in metadolerite dikes, Southeastern Bighorn Mountains. Wyom Am Mineral 59(7):656-665 
Beltenev V, Ivanov V, Rozhdestvenskaya I, Cherkashov G, Stepanova T, Shilov V, Pertsev A, Davydov M, Egorov I, Melekestseva I, Narkevsky E, Ignatov V (2007) A new hydrothermal field at $13^{\circ} 30^{\prime} \mathrm{N}$ on the Mid-Atlantic Ridge. InterRidge News 16:9-10

Beltenev V, Ivanov V, Rozhdestvenskaya I, Cherkashov G, Stepanova T, Shilov V, Davydov M, Laiba A, Kaylio V, Narkevsky E, Pertsev A, Dobretsova I, Gustaytis A, Popova Y, Amplieva E, Evrard C, Moskalev L, Gebruk A (2009) New data about hydrothermal fields on the Mid-tlantic Ridge between $11^{\circ}-14^{\circ} \mathrm{N}$ : 32 nd cruise of R/V professor Logatchev. InterRidge News 18:13-17

Biedermann AR, Pettke T, Angel RJ, Hirt AM (2016) Anisotropy of magnetic susceptibility in alkali feldspar and plagioclase. Geophys Suppl Royal Astron Soc 205(1):479-489

Bolle O, Diot H, Trindade RI (2003) Magnetic fabrics in the Holum granite (Vest-Agder, southernmost Norway): implications for the late evolution of the Sveconorwegian (Grenvillian) orogen of SW Scandinavia. Precambr Res 121(3):221-249

Bollmann W (1970) Crystal defects and crystalline interfaces. Springer, Heidelberg-Berlin

Bonatti E, Brunelli D, Buck WR, Cipriani A, Fabretti P, Ferrante V, Ligi GL (2005) Flexural uplift of a lithospheric slab near the Vema transform (Central Atlantic): timing and mechanisms. Earth Planet Sci Lett 240(3-4):642-655

Bown MG, Gay P (1959) The identification of oriented inclusions in pyroxene crystals. Am Miner 44(5-6):592-602

Calvín P, Ruiz-Martínez VC, Villalaín JJ, Casas-Sainz AM, Moussaid B (2017) Emplacement and deformation of Mesozoic gabbros of the High Atlas (Morocco): paleomagnetism and magnetic fabrics. Tectonics 36(12):3012-3037

Cipriani A, Bonatti E, Ligi BD (2009) 26 million years of mantle upwelling below a segment of the Mid Atlantic Ridge: the Vema Lithospheric section revisited. Earth Planet Sci Lett 285(1-2):87-95

Cottrell RD, Tarduno JA (1999) Geomagnetic paleointensity derived from single plagioclase crystals. Earth Planet Sci Lett 169:1-5

Dick HJB, MacLeod CJ, Blum P, Abe N, Blackman DK, Bowles JA, Cheadle MJ, Cho K, Ciążela J, Deans JR, Edgcomb VP, Ferrando C, France L, Ghosh B, Ildefonse BM, Kendrick MA, Koepke JH, Leong JAM, Liu C, Ma Q, Morishita T, Morris A, Natland JH, Nozaka T, Pluemper O, Sanfilippo A, Sylvan JB, Tivey MA, Tribuzio R, Viegas LGF (2017) Expedition 360 summary. In MacLeod CJ, DickHJB, Blum P, and the Expedition 360 Scientists, Southwest Indian Ridge Lower Crust andMoho. Proceedings of the Inter- national Ocean Discovery Program, 360: College Station, TX(International Ocean Discovery Program). 10.14379/iodp.proc.360.101.2017

Dick HJB, MacLeod CJ, Blum P, Abe N, Blackman DK, Bowles JA et al (1473A) Dynamic accretion beneath a slow-spreading ridge segment: IODP Hole 1473A and the Atlantis Bank Oceanic Core Complex. J Geophys Res Earth. https://doi. org/10.1029/2018JB016858

Diot H, Bolle O, Lambert JM, Launeau P, Duchesne JC (2003) The Tellnes ilmenite deposit (Rogaland, South Norway): magnetic and petrofabric evidence for emplacement of a Ti-enriched noritic crystal mush in a fracture zone. J Struct Geol 25(4):481-501

Divljan S, (1960) The results of field and laboratory studies of aventurine plagioclases from some Norwegian pegmatites. Proceedings of the 21st International Geological Congress, Norden 17: 94-101.

Doukhan N, Ingrin J, Doukhan JC, Latrous K (1990) Coprecipitation of magnetite and amphibole in black star diopside; a TEM study. Am Miner 75(7-8):840-846

Dunlop DJ, Ozdemir O (1997) Rock Magnetism. Cambridge University Press, Cambridge

Dunlop DJ, Özdemir O, Kono M (2007) Magnetizations of rocks and minerals. Treatise Geophys 5:277-336
Ebert Y, Kessel R, Shaar R, Agnon A, Ron H (2010) Petrology and rock magnetism of the gabbro of Troodos ophiolite. Phys Earth Planet Inter 183(3-4):413-420

Evans ME, McElhinny MW, Gifford AC (1968) Single domain magnetite and high coercivities in a gabbroic intrusion. Earth Planet Sci Lett 4(2):142-146

Feinberg JM, Wenk HR, Renne PR, Scott GR (2004) Epitaxial relationships of clinopyroxene-hosted magnetite determined using electron backscatter diffraction (EBSD) technique. Am Miner 89(2-3):462-466

Feinberg JM, Scott GR, Renne PR, Wenk HR (2005) Exsolved magnetite inclusions in silicates: features determining their remanence behavior. Geology 33(6):513-516

Feinberg JM, Wenk HR, Scott GR, Renne PR (2006) Preferred orientation and anisotropy of seismic and magnetic properties in gabbronorites from the Bushveld layered intrusion. Tectonophysics 420(3-4):345-356

Fleet ME (1986) The structure of magnetite: symmetry of cubic spinels. J Solid State Chem 62(1):75-82

Fleet ME, Gregory AB, Robert L (1980) Oriented magnetite inclusions in pyroxenes from the Grenville Province. Can Mineral 18(1):89-99

Gee J, Meurer WP (2002) Slow cooling of middle and lower oceanic crust inferred from multicomponent magnetizations of gabbroic rocks from the Mid-Atlantic ridge South of the Kane fracture zone (MARK) area. J Geophys Res Solid Earth 107(7):3

Godard M, Awaji S, Hansen H, Hellebrand E, Brunelli D, Johnson K, Yamasaki T, Maeda J, Abratis M, Christie D, Kato Y (2009) Geochemistry of a long in-situ section of intrusive slow-spread oceanic lithosphere: results from IODP Site U1309 (Atlantis Massif, $30 \mathrm{~N}$ Mid-Atlantic-Ridge). Earth Planet Sci Lett 279(1-2):110-122

Griffiths TA, Habler G, Abart R (2016) Crystallographic orientation relationships in host-inclusion systems: new insights from large EBSD data sets. Am Miner 101(3):690-705

Grimes CB (2008) Duration, rates, and patterns of crustal growth at slow-spreading mid-ocean ridges: using zircon to investigate the evolution of in situ ocean crust Dissertation. University of Wyoming, Wyoming

Harlow GE, Klimentidis R (1980) Clouding of Pyroxenes and Plagioclases in Eucrites: Implications for Post-Crystallization Processing. Lunar and Planetary Science Conference.

Hekinian R (2014) Earth's Mantle Melting and Volcanism. Sea Floor Exploration 1:109-143

Hwang SL, Shen P, Chu YTF, HT, (2010) On the coherency-controlled growth habit of precipitates in minerals. J Appl Cryst 43:417-428

Krakow R, Bennett RJ, Johnstone DN, Vukmanovic Z, Solano-Alvarez W, Lainé SJ, Einsle JF, Midgley PA, Rae CMF, Hielscher R (2017) On three-dimensional misorientation spaces. Royal Soc Mathe Phys Eng Sci 473(2206):20170274

Malpas JG, Robinson PT (1997) New Series: The Origin and Evolution of Oceanic Lithosphère. Geosci CA 24(2):12

Muxworthy AR, Evans ME (2013) Micromagnetics and magnetomineralogy of ultrafine magnetite inclusions in the Modipe Gabbro. Geochem Geophys Geosyst 14(4):921-928

Natland JH, Meyer PS, Dick HJ, Bloomer SH (1991) Magmatic oxides and sulfides in gabbroic rocks from Hole 735B and the later development of the liquid line of descent. Von Herzen, RP, Robinson, PT, et al., Proc. ODP. Sci Results 118:75-111

Neumann H, Christie OHJ (1962) Observation of plagioclase aventurines from Southern Norway. Nor Geol Tidsskr 42(2):389-393

Okamura FP, McCallum IS, Stroh JM, Ghose S (1976) Pyroxene-spinel intergrowths in lunar and terrestrial pyroxenes. Lunar Planet Sci Conf Proc 7:1889-1899

Pertsev AN, Bortnikov NS, Vlasov EA, Beltenev VE, Dobretsova IG, Ageeva OA (2012) Recent massive sulfide deposits of the 
Semenov ore district, Mid-Atlantic Ridge, $13^{\circ} 31^{\prime} \mathrm{N}$ : associated rocks of the oceanic core complex and their hydrothermal alteration. Geol Ore Deposits 54(5):334-346

Pertsev AN, Aranovich LY, Prokofiev VY, Bortnikov NS, Cipriani A, Simakin SS, Borisovskiy SE (2015) Signatures of residual melts, magmatic and seawater-derived fluids in oceanic lower-crust gabbro from the Vema lithospheric section, Central Atlantic. J Petrol 56(6):1069-1088

Poldervaart A, Gilkey AK (1954) On clouded feldspars. Am Miner 39:75-91

Renne PR, Scott GR, Glen JM, Feinberg JM (2002) Oriented inclusions of magnetite in clinopyroxene: source of stable remanent magnetization in gabbros of the Messum Complex, Namibia. Geochem Geophys Geosyst 3(12):1-11

Ribbe PH (1984) Average structures of alkali and plagioclase feldspars: systematics and applications. Feldspars and Feldspathoids. Springer, Dordrecht, pp 1-54

Smith DK, Escartín J, Cann SH, JR, (2008) Fault rotation and core complex formation: significant processes in seafloor formation at slow-spreading mid-ocean ridges (Mid-Atlantic Ridge, 13-15 N). Geochem Geophys Geosyst 9(3):9

Sobolev PO (1990) Orientation of acicular iron-ore mineral inclusions in plagioclase. Internat Geol Rev 32(6):616-628

Sobolev PO, Faynberg FS (1990) Causes of remanent magnetization in the gabbronorite of the Burakovskiy pluton. Trans (Dokl) USSR Acad Sci Earth Sci Sect 314(5):92-96

Suhr G, Hellebrand E, Johnson K, Brunelli D (2008) Stacked gabbro units andintervening mantle: a detailed look at a section of IODP Leg 305, Hole U1309D. Geochem Geophys Geosyst 9(10):7

Sutton A, Balluffi R (1995) Interfaces in crystalline materials. Oxford Scientific Publications, Oxford

Tan W, He H, Wang CY, Dong H, Liang X, Zhu J (2016) Magnetite exsolution in ilmenite from the Fe-Ti oxide gabbro in the Xinjie intrusion (SW China) and sources of unusually strong remnant magnetization. Am Miner 101(12):2759-2767

Tarduno JA, Cottrell RD, Smirnov AV (2006) The paleomagnetism of single silicate crystals: Recording geomagnetic field strength during mixed polarity intervals, superchrons, and inner core growth. Rev Geophys 44(1):98

Tauxe L (2010) Essentials of paleomagnetism. University of California Press, Berkeley
Trindade RI, Raposo MIB, Ernesto M, Siqueira R (1999) Magnetic susceptibility and partial anhysteretic remanence anisotropies in the magnetite-bearing granite pluton of Tourão. NE Br Tectonophys 314(4):443-468

Trindade RI, Bouchez JL, Bolle O, Nédélec A, Peschler A, Poitrasson F (2001) Secondary fabrics revealed by remanence anisotropy: methodological study and examples from plutonic rocks. Geophys J Internat 147(2):310-318

Usui Y, Nakamura N, Yoshida T (2006) Magnetite microexsolutions in silicate and magmatic flow fabric of the Goyozan granitoid (NE Japan): significance of partial remanence anisotropy. J Geophys Res Solid Earth 111(11):1978-2012

Usui Y, Shibuya T, Sawaki Y, Komiya T (2015) Rock magnetism of tiny exsolved magnetite in plagioclase from a Paleoarchean granitoid in the Pilbara craton. Geochem Geophys Geosyst 16(1):112-125

Villiger S, Ulmer P, Müntener O (2007) Equilibrium and fractional crystallization experiments at $0.7 \mathrm{GPa}$; the effect of pressure on phase relations and liquid compositions of tholeiitic magmas. $\mathrm{J}$ Petrol 48(1):159-184

Wenk HR, Joswig W, Tagai T, Korekawa M, Smith BK (1980) The average structure of An 62-66 labradorite. Am Miner 65(1-2):81-95

Wenk HR, Chen K, Smith R (2011) Morphology and microstructure of magnetite and ilmenite inclusions in plagioclase from Adirondack anorthositic gneiss. Am Mineral 96(8-9):1316-1324

Winter JK, Okamura FP, Ghose S (1979) A high-temperature structural study of high albite, monalbite, and the analbite- $>$ monalbite phase transition. Am Miner 64(3-4):409-423

Woensdregt CF, Weibel M, Wessicken R (1983) Electron microscopical investigation of oriented magnetite and amphibole in black star diopside. Schweiz Mineral Petrogr Mitt 63(2-3):167-176

Publisher's Note Springer Nature remains neutral with regard to jurisdictional claims in published maps and institutional affiliations. 